\title{
Reporter Assays for Ebola Virus Nucleoprotein Oligomerization, Virion-Like Particle Budding, and Minigenome Activity Reveal the Importance of Nucleoprotein Amino Acid Position 111
}

\author{
Aaron E. Lin $1,2,3, *,+$, William E. Diehl ${ }^{4,+}{ }^{(}$, Yingyun Cai ${ }^{5}\left(\mathbb{D}\right.$, Courtney L. Finch ${ }^{5}$, \\ Chidiebere Akusobi ${ }^{6}$, Robert N. Kirchdoerfer ${ }^{7}$, Laura Bollinger ${ }^{5}$, Stephen F. Schaffner ${ }^{2,3}{ }^{(1)}$, \\ Elizabeth A. Brown 2,3, Erica Ollmann Saphire ${ }^{8}$, Kristian G. Andersen 9,10 , Jens H. Kuhn 5, ${ }^{\text {(D), }}$ \\ Jeremy Luban ${ }^{4, \ddagger}$ (D) and Pardis C. Sabeti $1,2,3,11, *, \ddagger$ \\ 1 Harvard Program in Virology, Harvard Medical School, Boston, MA 02115, USA \\ 2 Department of Organismic and Evolutionary Biology, FAS Center for Systems Biology, Harvard University, \\ Cambridge, MA 02138, USA; sfs@broadinstitute.org (S.F.S.); eabrown21@gmail.com (E.A.B.) \\ 3 Broad Institute of MIT and Harvard, Cambridge, MA 02142, USA \\ 4 Program in Molecular Medicine, University of Massachusetts Medical School, Worcester, MA 01605, USA; \\ William.Diehl@umassmed.edu (W.E.D.); Jeremy.Luban@umassmed.edu (J.L.) \\ 5 Integrated Research Facility at Fort Detrick, National Institute of Allergy and Infectious Diseases, National \\ Institutes of Health, Frederick, MD 21702, USA; caiy@niaid.nih.gov (Y.C.); courtney.finch@nih.gov (C.L.F.); \\ laura.bollinger@nih.gov (L.B.); kuhnjens@niaid.nih.gov (J.H.K.) \\ 6 Department of Immunology and Infectious Diseases, Harvard T.H. Chan School of Public Health, Boston, \\ MA 02120, USA; Chidiebere_Akusobi@hms.harvard.edu \\ 7 Department of Biochemistry, University of Wisconsin-Madison, Madison, WI 53706, USA; \\ rnkirchdoerf@wisc.edu \\ $8 \quad$ La Jolla Institute for Immunology, La Jolla, CA 92037, USA; erica@lji.org \\ 9 Department of Immunology and Microbial Sciences, The Scripps Research Institute, La Jolla, CA 92037, USA; \\ kristian@andersen-lab.com \\ 10 Scripps Translational Science Institute, La Jolla, CA 92037, USA \\ 11 Howard Hughes Medical Institute, Chevy Chase, MD 20815, USA \\ * Correspondence: alin@broadinstitute.org (A.E.L.); pardis@broadinstitute.org (P.C.S.) \\ + These authors contributed equally to this work. \\ $\ddagger \quad$ These authors contributed equally to this work.
}

Received: 10 December 2019; Accepted: 13 January 2020; Published: 15 January 2020

check for updates

\begin{abstract}
For highly pathogenic viruses, reporter assays that can be rapidly performed are critically needed to identify potentially functional mutations for further study under maximal containment (e.g., biosafety level 4 [BSL-4]). The Ebola virus nucleoprotein (NP) plays multiple essential roles during the viral life cycle, yet few tools exist to study the protein under BSL-2 or equivalent containment. Therefore, we adapted reporter assays to measure NP oligomerization and virion-like particle (VLP) production in live cells and further measured transcription and replication using established minigenome assays. As a proof-of-concept, we examined the NP-R111C substitution, which emerged during the 2013-2016 Western African Ebola virus disease epidemic and rose to high frequency. NP-R111C slightly increased NP oligomerization and VLP budding but slightly decreased transcription and replication. By contrast, a synthetic charge-reversal mutant, NP-R111E, greatly increased oligomerization but abrogated transcription and replication. These results are intriguing in light of recent structures of NP oligomers, which reveal that the neighboring residue, K110, forms a salt bridge with E349 on adjacent NP molecules. By developing and utilizing multiple reporter assays, we find that the NP-111 position mediates a complex interplay between NP's roles in protein structure, virion budding, and transcription and replication.
\end{abstract}


Keywords: Ebola virus; nucleoprotein; budding; oligomerization; reporter assays; viral evolution

\section{Introduction}

Ebola virus (EBOV) remains a serious hazard to human health; however, studying live virus requires maximum (biosafety level 4 [BSL-4]) containment, restricting experiments to a handful of laboratories around the globe. Therefore, reporter assays can complement live virus experiments in two ways. First, reporter assays can selectively study one or a handful of viral phenotypes for better understanding of specific molecular mechanisms. Second, many reporter assays can be performed at BSL-1 or -2 containment, expanding performance of EBOV studies to many more laboratories. Therefore, reporter assays can be a first-line tool to assess how rapidly evolving viral genotypes affect phenotype before time- and resource-intensive BSL-4 studies are conducted.

Given the past and current public health threats caused by Ebola virus disease (EVD) outbreaks, rapidly evaluating whether EBOV genomic mutations change viral phenotypes is critically important. As an RNA virus, EBOV generates many mutations over the course of an outbreak. The vast majority of these mutations likely will not be adaptive and will instead have negligible or negative effects on EBOV viability and replication [1]. Yet, changes in the EBOV genome over time can have important implications for clinical patient care, epidemiological modeling, and vaccine development and, thus, can influence prospective outbreak prediction and response.

The need to better understand EBOV evolution became clear during the 2013-2016 EVD epidemic in Western Africa caused by the EBOV Makona variant. This epidemic is the largest EVD epidemic on record with over 28,000 infections and more than 11,000 deaths [2]. EBOV replication generated thousands of mutations over numerous rounds of human-to-human transmission [3-14], but only a handful of mutations became common enough to have had a sizeable impact on the epidemic [3-9]. One key mutation, C6283U, results in an A82V substitution in the EBOV glycoprotein (GP-A82V) and has been studied extensively through well-established BSL-2 surrogate model systems and live virus BSL-4 studies. GP-A82V increases EBOV infectivity in human and other primate cell types in vitro, suggesting that the mutation confers a selective advantage to EBOV [15-20]. However, increased EBOV infectivity has not yet been demonstrated clearly in vivo [21,22].

A second high-frequency mutation that emerged amidst the epidemic, C800U, results in an R111C substitution in the EBOV nucleoprotein (NP-R111C). Both the GP-A82V and NP-R111C substitutions arose on the same viral lineage and rose to $>90 \%$ frequency. In contrast to GP-A82V, NP-R111C has not been thoroughly studied. Though NP has many functions, a limited number of assays are available for studying these functions. This limitation presents an important challenge and opportunity to develop assays to gain mechanistic insight into NP biology and variation.

The N-terminal domain of EBOV NP, which contains the R111 residue, is necessary and sufficient to drive oligomerization of NP monomers into long, flexible helices. These oligomers help shape virions and coat viral RNA during the viral life cycle. Many studies have determined NP structures and modeled how NP interacts with itself and RNA [23-29]. In addition to a flexible oligomerization domain (OD) at the very $\mathrm{N}$ terminus of NP that is essential for oligomerization, numerous other residues appear to be involved in NP-NP interactions as visualized in cryo-electron microscopy (cryo-EM) of helical NP oligomers [26-30]. Between vertically adjacent NP proteins, NP-K110 on one monomer appears to form a salt bridge with NP-E349 on another monomer [28,29]. No naturally occurring mutations have been shown to affect EBOV NP oligomerization, though the proximity of NP-R111 to the NP-K110 residue suggests that the NP-R111C substitution could affect oligomerization. Although many biochemical methods are available for assessing NP oligomerization in vitro, few assays exist to quantitatively measure oligomerization in live cells.

The ability of NP to oligomerize likely affects its role in virion assembly and budding. During the viral life cycle, the EBOV matrix protein VP40 induces curvature of the cell's plasma membrane and 
engages with EBOV nucleocapsids (composed of NP oligomers, polymerase cofactor VP35, and minor capsid protein VP24) to form EBOV particles that exit the cell by budding [31]. Expression of VP40 alone generates similarly shaped particles, dubbed virion-like particles (VLPs) [32-34]. Co-expression of NP with VP40 significantly increases the number of VLPs released from cells [35], but the mechanism by which NP increases VLP production is not fully elucidated. For example, NP oligomers could physically stabilize VLP structure, or NP could engage with host proteins to promote VLP assembly and budding.

EBOV NP oligomers also play an essential role in viral transcription and replication. By directly interacting with EBOV RNA, VP35, and transcription regulator VP30, NP recruits the RNA-directed RNA polymerase $L$ to enact both of these essential functions [36]. NP structural data, homology modeling to other viral nucleoproteins, and site-directed mutagenesis experiments have identified key EBOV NP residues that interact with EBOV RNA [23-25], VP35 [24,25], and VP30 [37]. The NP residue 111 lies outside of any of these annotated interaction surfaces, suggesting that NP-R111C most likely does not directly affect binding affinity to RNA. However, only NP oligomers, and not NP monomers, bind RNA $[24,25,27]$, so mutations that affect NP oligomerization propensity could still impact RNA binding avidity and thereby influence transcription and replication.

For this study, we adapted and modified BSL-2 methods to study key functions of EBOV NP in cell culture-oligomerization and VLP budding—and used established minigenome systems to measure viral transcription and replication. Such tools are critical for rapidly characterizing unknown or emerging mutants since studying live EBOV requires limited BSL-4 facilities. Moreover, existing recombinant live virus systems typically use a genetic backbone that is different from the EBOV Makona variant isolate C-15 sequence [38-41], and generating new recombinant systems remains logistically and financially challenging due to restrictions on their use and associated synthesis costs. Using these straightforward, modular reporter assays, we found that the NP-R111C substitution slightly increased EBOV NP oligomerization and VLP budding and slightly decreased transcription and replication. Charge-reversal at this position, NP-R111E, significantly altered NP oligomerization, supporting the K110-E349 salt bridge in cryo-EM structures of NP oligomers. Unexpectedly, NP-R111E dramatically ablated viral transcription and replication. Our findings demonstrate the interconnectedness of multiple viral phenotypes controlled by the NP-R111 residue and support the possibility that NP-R111C affects replication of live virus.

\section{Materials and Methods}

\subsection{Key Resources Table}

We attached a Key Resources Table, including oligonucleotide sequences, as Supplementary File S1.

\subsection{Ebola Virus Genome Sequences and Phylogenetic Analysis}

We obtained Ebola virus (EBOV) genomes from the US National Institute of Allergy and Infectious Diseases (NIAID) Virus Pathogen Database and Analysis Resource (ViPR) through the web site at http://www.viprbrc.org/ [42] in October 2017. We removed short sequences, sequences from tissue-cultured EBOV isolates, duplicate sequences from the same clinical EVD case, and sequences with $>0.2 \%$ ambiguous or missing nucleotide calls. The final dataset consisted of 1823 EBOV complete or near-complete genomes.

We aligned these genomes with MAFFT v6.902b [43] using the parameters (L-INS-i): -localpair -maxiterate 1000 -reorder -ep 0.123. We trimmed the alignment using trimAl v1.4 [44] with -automated1. Lastly, we generated a maximum likelihood tree with RAxML v7.3.0 [45] under a generalized time-reversible (GTR $\gamma$ ) nucleotide substitution model with 100 bootstrap pseudoreplicates (Figure 1). 
A

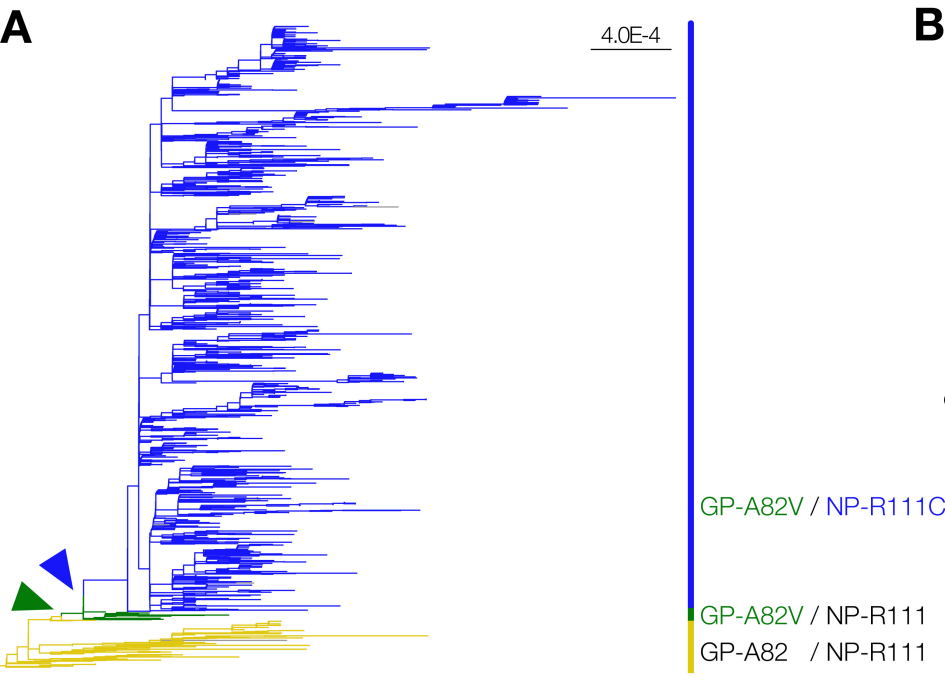

B

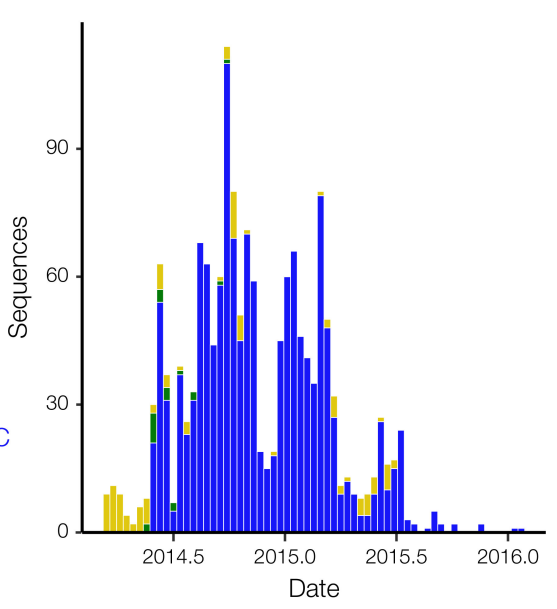

Figure 1. EBOV NP-R111C emerged alongside the GP-A82V substitution. (A) Phylogenetic analysis of the 2013-2016 EVD epidemic. We constructed a maximum likelihood tree based on 1,823 EBOV genome sequences, and colored branches based on GP-82 and NP-111 alleles. No GP-A82/NP-R111C sequences were detected. Arrowheads point to the emergence of the GP-A82V (green) and NP-R111C (blue) substitutions compared to genomes encoding the ancestral GP-A82/NP-R111 alleles (tan). Scale bar denotes substitutions/nucleotide; (B) Number of EVD cases over time, stratified by genotype. Coloring is identical to Figure $1 \mathrm{~A}$.

For cloning and functional characterization, we used the genome sequence of Ebola virus/H.sapiens-wt/GIN/2014/Makona-C15 (EBOV/Mak-C15; GenBank \#KJ660346.2; Filoviridae: Zaire ebolavirus) as the EBOV Makona variant reference sequence for NP, VP40, VP35, and GP, unless otherwise noted. The structural analysis of EBOV NP was based on the Ebola virus/H.sapiens-tc/COD/1976/Yambuku-Mayinga NP (EBOV/Yam-May) crystal structure under Protein Data Bank (PDB) \#4YPI [24], with manual annotation of key residues based on other studies [24,25]. The structure of EBOV/Mak-C15 NP has not yet been elucidated, but the amino acid sequence is $98 \%$ identical (14 mutations/739 residues) to EBOV/Yam-May NP, and the N-terminal 450 amino acids of the two isolates are 99.3\% identical (3 mutations/450 residues). The EBOV/Yam-May crystal structure \#4YPI was visualized using PyMOL (Schrödinger, New York City, NY, USA) (Figure 2) [46]. 
A

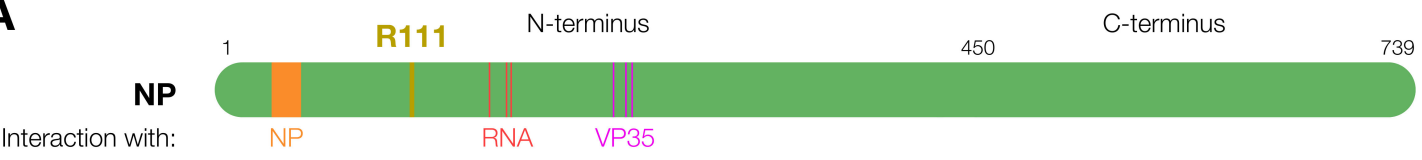

B
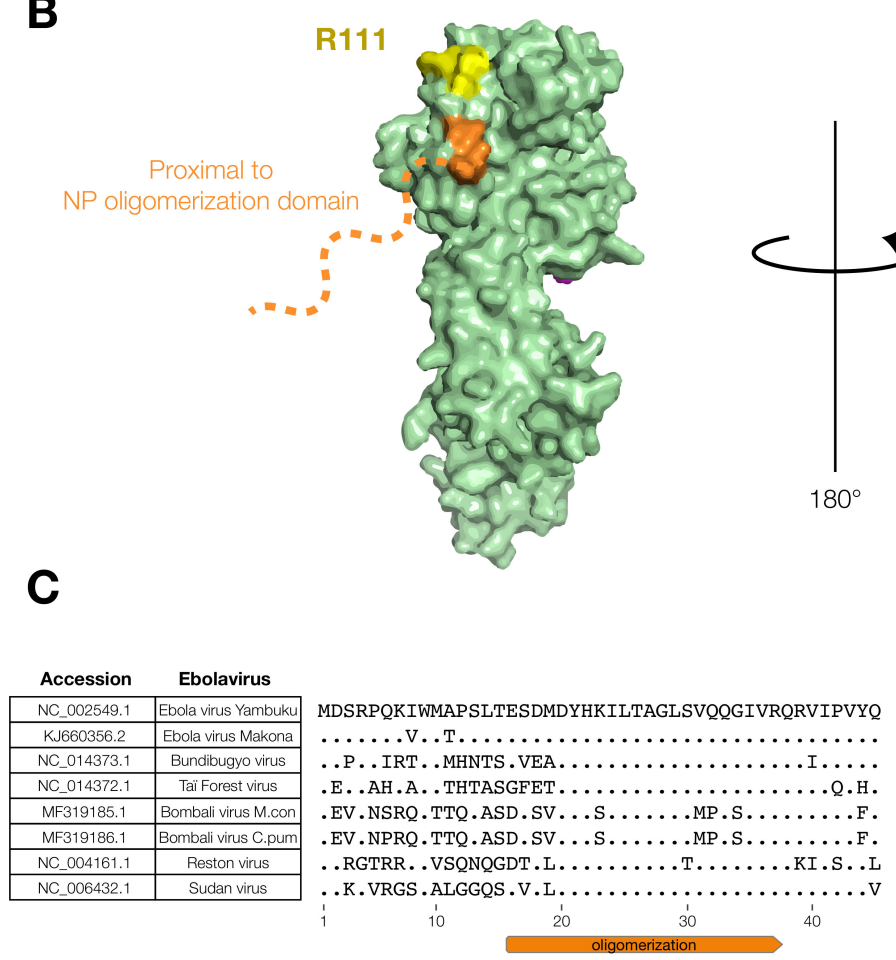
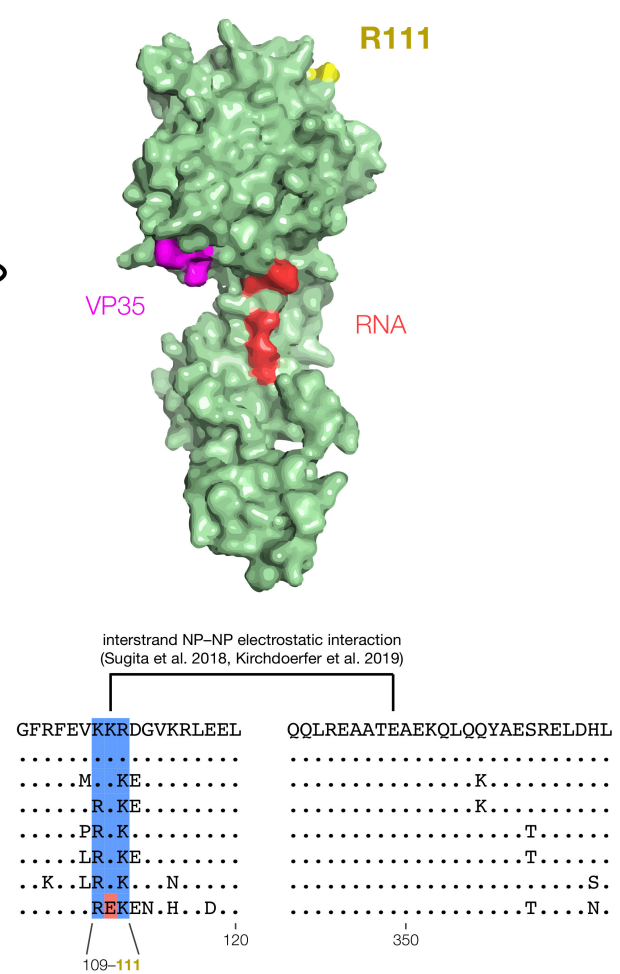

Figure 2. The EBOV NP-R111 residue is unannotated, but could impact NP-NP interaction. (A) Schematic of NP. R111 (yellow) lies in an un-annotated region within the N-terminal lobe. Key residues of known NP interactions are highlighted; (B) Crystal structure (PDB \#4YPI) of NP. Though the precise location of the oligomerization domain has yet to be determined by crystallography (orange dashed line), the R111 residue (yellow) is located on the same face as residues proximal to the oligomerization domain (orange: residues 39, 40), but opposite to the VP35 (magenta: residues 160, 171, 174) and RNA (red: residues 240, 248, 252) interaction interfaces; (C) Alignment of ebolavirus sequences. The basic residues at 109, 110, and 111 (blue), and a recently identified electrostatic interaction between K110 and E349 [28,29], are conserved in all known ebolaviruses except Sudan virus (SUDV, red).

\subsection{Constructs and Cloning}

We performed most assays with the same mammalian expression vector for EBOV/Mak-C15 NP and its mutants, except where indicated. We synthesized EBOV NP-R111 in 2 dsDNA gBlocks (Integrated DNA Technologies [IDT], Coralville, IA) and cloned these gBlocks into pGL4.23-CMV [15] modified with a C-terminal V5 peptide tag. To generate all NP mutants, we performed a modified site-directed mutagenesis (SDM) protocol, as described in [15]. For many assays, we expressed enhanced green fluorescent protein (eGFP) in cells in place of NP as a negative control. We generated the corresponding vector by cloning eGFP into pcDNA3.3-CMV (Thermo Fisher Scientific, Waltham, MA, USA) modified by an in-frame C-terminal V5 peptide tag.

For co-immunoprecipitation (co-IP) and oligomerization studies, we generated NP with different C-terminal tags in the pGL4.23-CMV backbone. For the traditional dual-tag co-IP-Western blot (WB) strategy in Supplementary Figure S1, we generated myc-tagged NP (pGL4.23-CMV/NP-myc). For the bioluminescence resonance energy transfer (BRET) oligomerization assay (Figure 3), we replaced the C-terminal V5 tag with either HaloTag or NanoLuc (NLuc) from the NanoBRET Nano-Glo Detection 
System (Promega, Madison, WI, USA). As a negative control, we removed NP amino acid residues 20-38, abrogating the oligomerization domain (NP- $\Delta \mathrm{OD})$ [25], by SDM.

For the BRET experiment to study the NP-VP35 interaction (Figure 3C), we modified the pcDNA3.3 backbone with a woodchuck hepatitis virus post-transcriptional regulatory element (WPRE) to increase insert expression, using pcDNA3.3/KLF4 (a gift from Derrick Rossi; Addgene, Cambridge, MA, USA; plasmid \#26815) [47] and pLV-WPRE/mCherry (a gift from Pantelis Tsoulfas; Addgene; plasmid \#36084) as source material. We then cloned in eGFP, porcine teschovirus $12 \mathrm{~A}$ 'self-cleaving' peptide (P2A) [48], and EBOV/Mak-C15 VP35 amino acids 1-80 containing the NP-binding peptide (NPBP) [25] from a gBlock (IDT) into a single open reading frame (eGFP-P2A-VP35[NPBP]) upstream of the WPRE, resulting in pcDNA3.3-WPRE/eGFP-P2A-VP35[NPBP]. As a negative control, we cloned a V5-tagged blue fluorescent protein mTagBFP2 into the pcDNA3.3-WPRE backbone, using mTagBFP2-pBAD (a gift from Michael Davidson; Addgene; plasmid \#54572) [49] as source material.

For the VLP budding assay (Figure 4 and Supplementary Figure S3), we constructed a plasmid to express NLuc fused to EBOV/Mak-C15 VP40 (NLuc-VP40). To create this plasmid, we obtained a pcDNA3.1(+)-based vector expressing $\beta$-lactamase (Bla) fused to EBOV/Yam-May VP40 (Bla-VP40) from the US National Institutes of Health (NIH)/NIAID Biodefense and Emerging Infections Research Resources Repository (BEI Resources, Manassas, VA, USA; \#NR-19813) [50]. We replaced the Bla sequence with the gene encoding NLuc from pNL1.1 (Promega) and replaced the EBOV/Yam-May VP40 sequence with that of EBOV/Mak-C15 VP40 from a gBlock (IDT). pNL1.1, which expresses NLuc alone without VP40, was used as a negative control. As an additional negative control, we performed SDM to introduce a L117R substitution into NLuc-VP40 to generate loss-of-function (LOF) [51]. For electron microscopy (Supplementary Figure S4), we additionally co-expressed EBOV glycoprotein (GP) from a pGL4.23-CMV vector [15].

For monocistronic (1MG) minigenome experiments (Figure 5B), plasmids are described in [52]. In this system, EBOV RNA-directed RNA polymerase (L), viral cofactor proteins (VP30 and VP35), and $\mathrm{NP}$ were derived from the EBOV/Yam-May isolate and expressed from a pCAGGS vector. We replaced EBOV/Yam-May NP with EBOV/Mak-C15 NP and its mutants before measuring minigenome activity encoded by a firefly luciferase (FLuc) reporter gene.

For tetracistronic (4MG) minigenome experiments (Figure 5C,D), we additionally cloned L and VP35 from EBOV/Mak-C15 into a pCAGGS vector. Since no amino acid differences are present between VP30 of EBOV/Yam-May and EBOV/Mak-C15, we were able to express EBOV/Mak-C15 sequences of all ribonucleoprotein (RNP) complex members (L, VP35, VP30, NP). We additionally cloned the 4MG minigenome plasmid from EBOV/Mak-C15, expressing a Renilla luciferase (RLuc) reporter gene, VP40, GP, and VP24. 
A

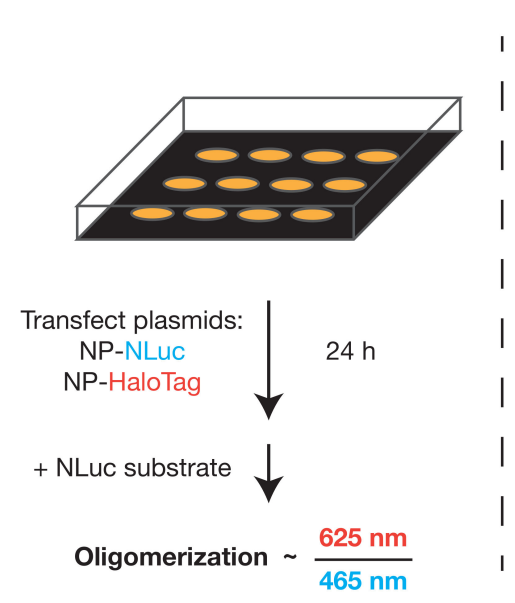

C

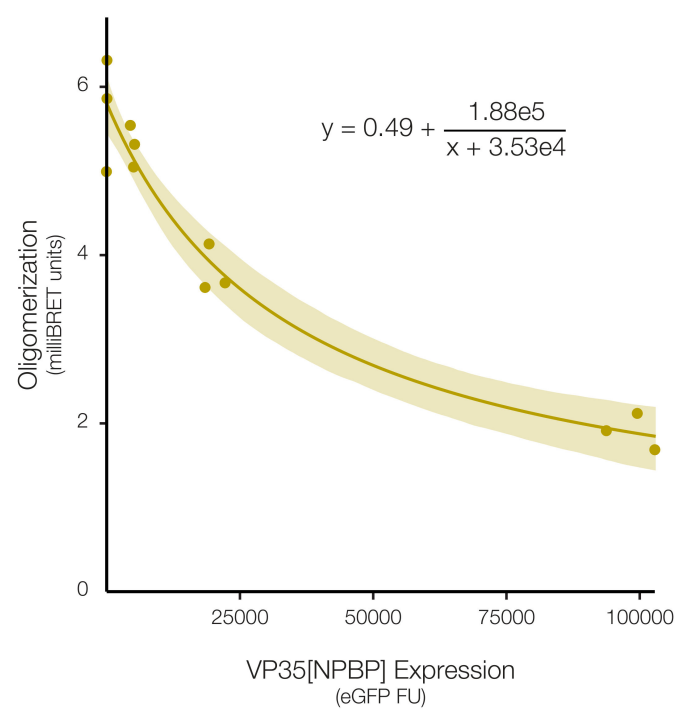

with 2 ng of NP-NLuc, 10 ng of NP-HaloTag
B

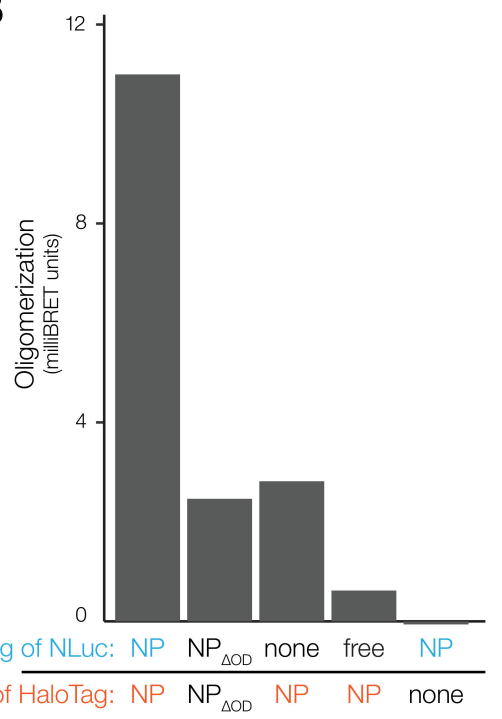

D
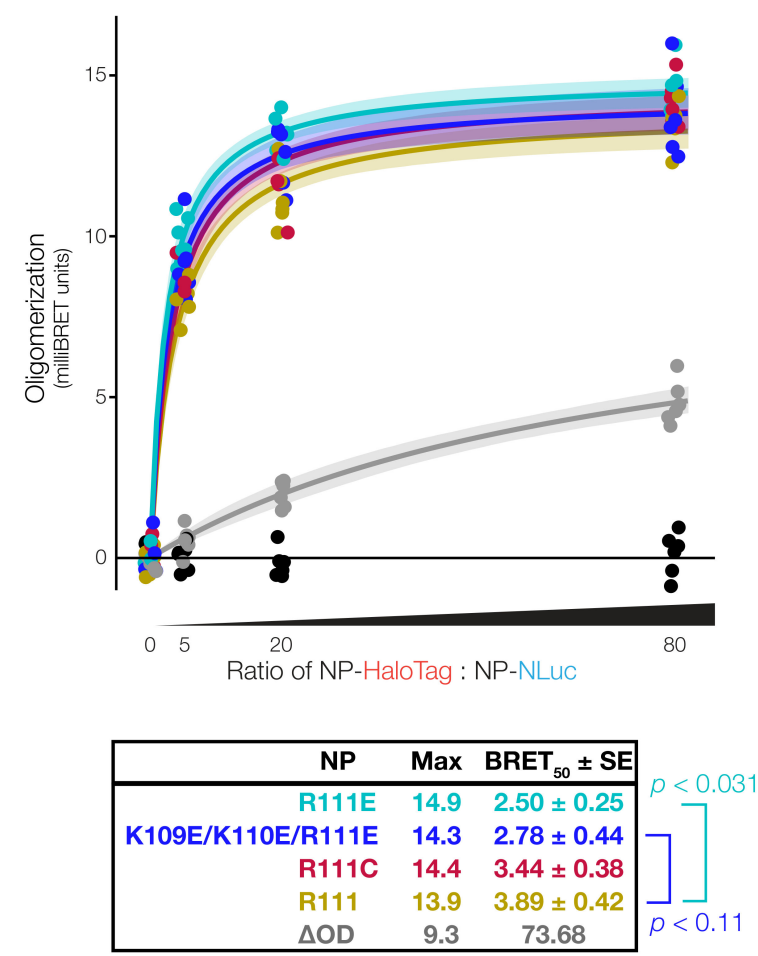

Figure 3. NP position 111 significantly affects oligomerization of NP. (A) Schematic of the NP oligomerization assay. We co-expressed NP fused to NanoLuc (NLuc, donor) and HaloTag (acceptor) in HEK 293FT cells. NP-NP binding and oligomerization brought the tags into close spatial proximity, producing bioluminescence resonance energy transfer (BRET) emission at $625 \mathrm{~nm}$. To calculate BRET signal in milliBRET units, we normalized $625 \mathrm{~nm}$ BRET luminescence against NP-NLuc luminescence at $465 \mathrm{~nm}$ and subtracted spectral spillover from NP-NLuc into the $625 \mathrm{~nm}$ channel; (B) BRET oligomerization assay controls. Absence of either tag, free NLuc (not fused to NP), or deletion of the NP oligomerization domain ( $\triangle \mathrm{OD}$, residues 20-38) reduced BRET signal; (C) EBOV VP35 NP-binding peptide (NPBP) disrupted NP oligomerization. In addition to NP-NLuc and NP-HaloTag, we co-expressed varying amounts of VP35[NPBP] in cells. To quantify VP35[NPBP] expression, we 
fused it to enhanced green fluorescent protein (eGFP), separated by a 'self-cleaving' porcine teschovirus $12 \mathrm{~A}$ peptide (P2A). We fitted oligomerization versus eGFP fluorescence units (FU) to an inverse function (Equation (1); $n=3$ biological replicates per VP35[NPBP] plasmid amount). Shading indicates $95 \%$ confidence intervals based on 999 bootstrap pseudoreplicates; (D) Donor saturation assay with NP mutants. We expressed a constant amount of NP-NLuc (donor) and expressed varying amounts of NP-HaloTag (acceptor) in cells to generate donor saturation curves (Equation (2); $n=6$ biological replicates per NP-HaloTag plasmid amount). We fitted data to saturation curves, calculated maximum oligomerization (Max) and ratio of NP-HaloTag to NP-NLuc plasmid needed to reach half Max \pm standard error $\left(\mathrm{BRET}_{50} \pm \mathrm{SE}\right.$ ) for each NP mutant. eGFP (black dots near $x$-axis) did not produce data suitable for curve fitting. We assessed statistical significance of differences in BRET ${ }_{50}$ between NP mutants by ANOVA with Dunnett's test to correct for multiple hypothesis testing. Shading indicates $95 \%$ confidence intervals based on 999 bootstrap pseudoreplicates.

A

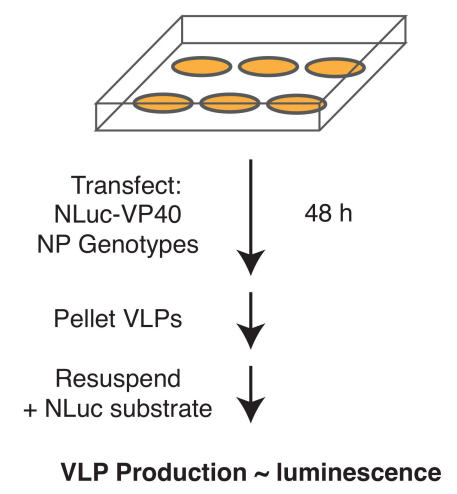

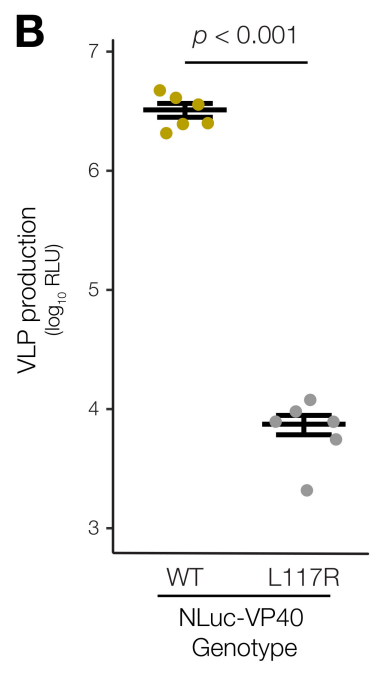

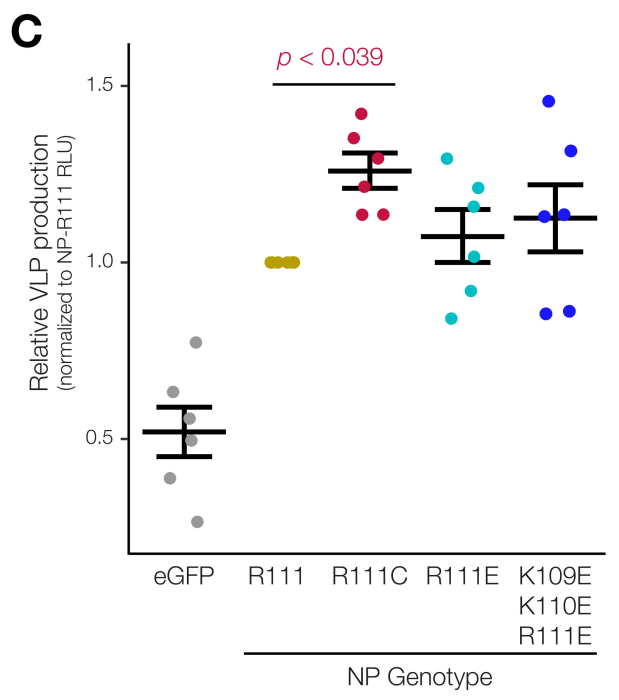

Figure 4. EBOV NP-R111C increases budding of VLPs. (A) Schematic of the VLP budding assay. We expressed NLuc fused to EBOV VP40 (NLuc-VP40) in HEK 293FT cells to form luminescent VLPs, and co-expressed NP mutants to measure the impact of NP genotype on VLP budding; (B) VLP budding assay control. NLuc-VP40 expression alone resulted in bright luminescence, expressed in relative light units (RLU). VP40 loss-of-function (LOF) mutant L117R failed to form VLPs ( $n=6$ biological replicates). We assessed statistical significance by paired $t$-test. Error bars indicate mean \pm standard error of the mean (SEM); (C) VLP budding with NP variants. We measured and normalized all NP or eGFP RLU values within each replicate to that replicate's NP-R111 RLU ( $n=6$ biological replicates) and assessed statistical significance using repeated measures ANOVA with Dunnett's test to correct for multiple hypothesis testing. Error bars indicate mean \pm SEM. 
A

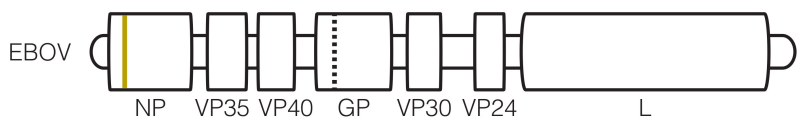

$1 M G$

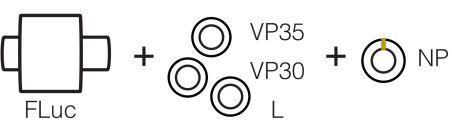

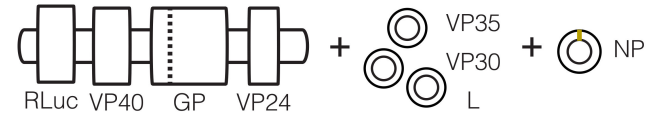

B

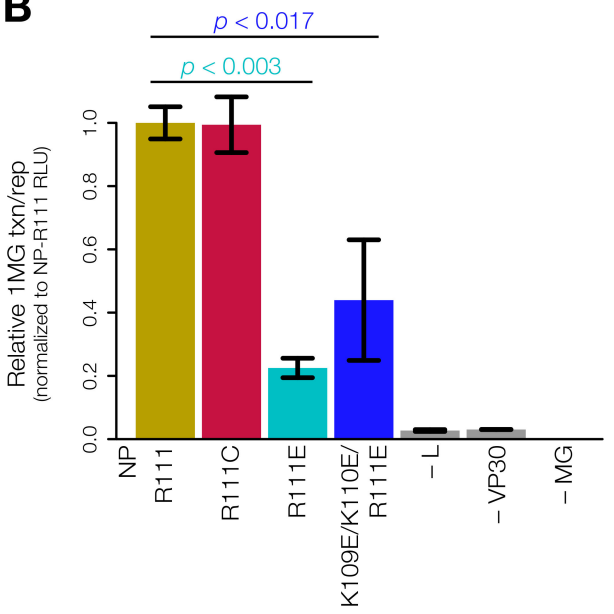

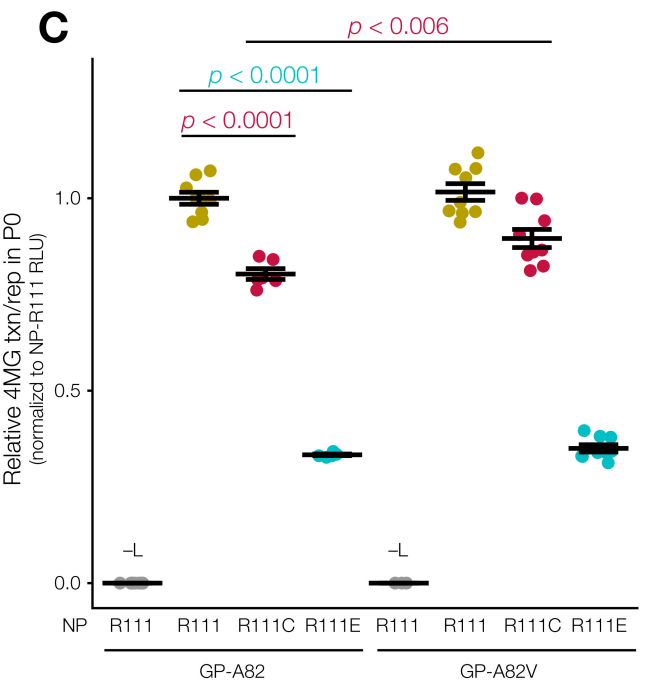

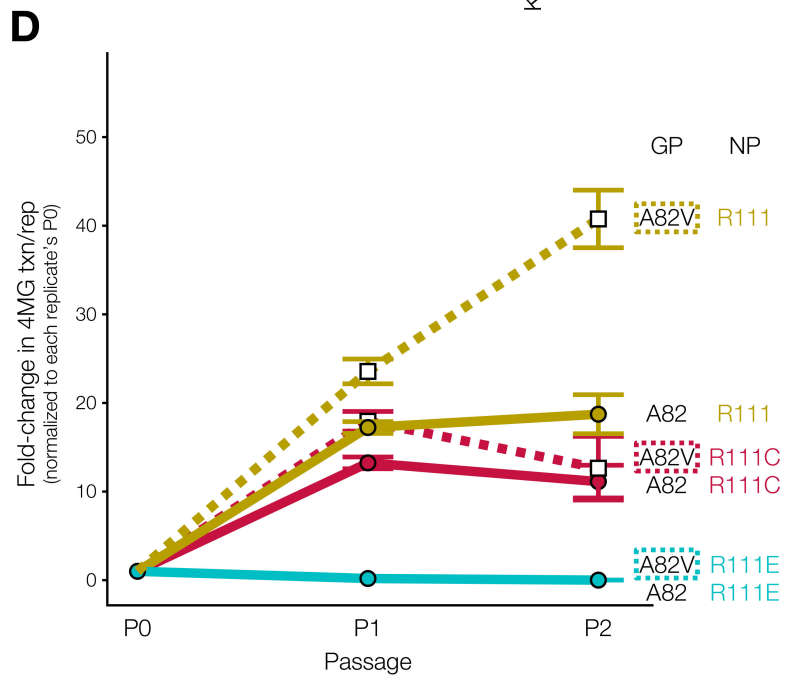

Figure 5. EBOV NP position 111 influences viral transcription and replication. (A) Schematic of monocistronic minigenome (1MG) and tetracistronic minigenome (4MG) systems. Compared to live virus genome (top), $1 \mathrm{MG}$ only encodes the EBOV leader and trailer sequences (middle), whereas the 4MG encodes the structural proteins VP40, GP, and VP24 (bottom). In both cases, the replication complex proteins (NP, VP35, VP30, and L) are expressed from plasmids in trans. Tan line indicates the position of NP-R111, and the dashed line indicates the position of GP-A82 (encoded on 4MG but not 1MG); (B) 1MG assay. We expressed NP mutants or ancestral NP-R111 in HEK 293T cells in the presence of the EBOV replication complex (L, VP35, VP30), and measured transcription and replication (txn/rep) of the 1MG minigenome encoding firefly luciferase (FLuc) relative to a Renilla luciferase (RLuc) loading control ( $n=3$ biological replicates). We normalized values to NP-R111. Absence of $\mathrm{L}$, VP30, or 1MG abolished FLuc signal. Both NP-R111E and NP-K109E/K110E/R111E charge-reversal mutants significantly decreased $1 \mathrm{MG}$ activity (ANOVA-Dunnett's test). Error bars indicate mean \pm SEM; (C) P0 producer cells of 4MG assay. We expressed transcription- and replication-competent (tr)VLPs harboring GP-A82 (left) or GP-A82V (right) and NP mutants in HEK 293T cells, and measured $4 \mathrm{MG}$ minigenome activity (RLuc) relative to an FLuc loading control ( $n=3-9$ biological replicates). We normalized values to GP-A82/NP-R111 and assessed statistical significance by ANOVA with Tukey's test (ANOVA-Tukey's test) to correct for multiple hypothesis testing. Error bars indicate mean \pm SEM; (D) Target P1 and P2 cells of 4MG assay. We expressed the EBOV replication complex in P1 Huh7 cells, and then infected P1 cells with P0 trVLPs, and measured 4MG activity. We repeated the process by expressing the EBOV replication complex in P2 Huh7 cells, infecting P2 cells with P1 trVLPs, and measuring $4 \mathrm{MG}$ activity again ( $n=3-9$ biological replicates). We normalized values for cells in each biological replicate to its own P0 activity and assessed statistical significance by ANOVA-Tukey's test. Solid lines and filled circles indicate GP-A82, whereas dashed lines and open squares indicate GP-A82V. Error bars indicate mean \pm SEM. 


\subsection{Cell Culture and Plasmid Transfections}

Unless otherwise specified, we grew human embryonic kidney (HEK) 293FT cells (Thermo Fisher Scientific; \#R70007) in Dulbecco's modified Eagle medium (DMEM) containing 10\% fetal bovine serum (FBS), $100 \mathrm{U} / \mathrm{mL}$ penicillin/streptomycin, non-essential amino acids, and sodium pyruvate (Thermo Fisher Scientific), at $37^{\circ} \mathrm{C}$ with $5 \% \mathrm{CO}_{2}$.

For most assays, we performed lipid-based reverse transfection using Lipofectamine 2000 (Thermo Fisher Scientific). For a 6-well plate, we incubated $2 \mu \mathrm{g}$ of plasmid DNA with $125 \mu \mathrm{L}$ of Opti-MEM (Thermo Fisher Scientific) at room temperature for $5 \mathrm{~min}$ (min). We incubated this mixture with $10 \mu \mathrm{L}$ of Lipofectamine 2000 in $115 \mu \mathrm{L}$ of Opti-MEM at room temperature for $45 \mathrm{~min}$. We added all $250 \mu \mathrm{L}$ of the DNA-lipid mixture to a well of a 6-well plate and then added trypsin-harvested cells. For smaller or larger plates, amounts were scaled accordingly. For BRET experiments, we used Opti-MEM without phenol red (Thermo Fisher Scientific) to minimize background fluorescence from culture media.

For the $1 \mathrm{MG}$ and $4 \mathrm{MG}$ minigenome assays and EM, we performed forward transfection by incubating DNA with TransIT-LT1 Transfection Reagent (Mirus Bio, Madison, WI, USA) in a 1:3 DNA:reagent ratio in Opti-MEM for 15-20 $\mathrm{min}$ at room temperature, and then added the mixture dropwise onto cells in 6- or 12-well plates.

\subsection{Co-Immunoprecipitation and Western Blot}

We washed cells in 6-well plates with phosphate-buffered saline (PBS), harvested by scraping, pelleted and resuspended cells in $30 \mu \mathrm{L}$ of $1.2 \%(w / v)$ polyvinylpyrrolidine (PVP) in $20 \mathrm{mM}$ K-HEPES buffer $\mathrm{pH} 7.4$, and snap-froze with liquid nitrogen. We lysed cells with 250-500 $\mu \mathrm{L}$ of pre-chilled lysis buffer with end-over-end rotation at $4{ }^{\circ} \mathrm{C}$ for $30 \mathrm{~min}$, cleared lysate of membranous debris by centrifugation at $8000 \times g$ at $4{ }^{\circ} \mathrm{C}$ for $10 \mathrm{~min}$, and saved an aliquot as input. To capture the target protein, we prepared a mixture of $25 \mu \mathrm{L}$ each of Protein A and Protein G SureBeads Magnetic Beads (Bio-Rad, Hercules, CA, USA) and immobilized 1-2 $\mu$ g of primary antibody on the beads by rotation at room temperature for $20 \mathrm{~min}$. We washed the bead-antibody complexes thrice with lysis buffer, and then incubated with cleared cell lysate while rotating the mixture at $4{ }^{\circ} \mathrm{C}$ for 2 hours (h). After capture, we washed beads six times with wash buffer followed by a final wash with PBS, and eluted proteins by boiling the beads in $50 \mu \mathrm{L}$ of Laemmli sample buffer (Bio-Rad) at $95^{\circ} \mathrm{C}$ for $10 \mathrm{~min}$.

We loaded the specified amount of input into denaturing $10 \%$ polyacrylamide (PAGE) gels, and performed electrophoresis at $180 \mathrm{~V}$ until complete. We transferred proteins to Immun-Blot PVDF Membranes (Bio-Rad) in a wet tank either at $200 \mathrm{~mA}$ for $1.5 \mathrm{~h}$ at $4{ }^{\circ} \mathrm{C}$, or at $40 \mathrm{~V}$ overnight at $4{ }^{\circ} \mathrm{C}$. We blocked membranes by rocking in blocking buffer consisting of $5 \%$ non-fat dry milk (Santa Cruz Biotechnology, Dallas, TX, USA) dissolved in tris-buffered saline with $0.1 \%$ Tween 20 (TBS-T) for $1 \mathrm{~h}$ at room temperature. We incubated membranes with primary antibody in blocking buffer for $45 \mathrm{~min}$, washed three times in TBS-T buffer, incubated the membrane with horseradish peroxidase-conjugated secondary antibody in blocking buffer for $1 \mathrm{~h}$, and washed three additional times. We activated chemiluminesence with SuperSignal West Pico Chemiluminescent Substrate (Thermo Fisher Scientific) and imaged with an AlphaInnotech ChemiImager (ProteinSimple, San Jose, CA, USA) or FluorChem E (ProteinSimple).

For the dual-tag co-IP-WB for NP oligomerization (Supplementary Figure S1), we used RIPA buffer $(50 \mathrm{mM}$ Tris pH $6.8,150 \mathrm{mM} \mathrm{NaCl}, 0.5 \%(w / v)$ sodium deoxycholate, $1 \%(w / v)$ Triton X-100 (Sigma-Aldrich, St. Louis, MO, USA)) both as the lysis and wash buffer because the NP-NP interaction was very strong [53].

For mass spectrometry (Supplementary Figure S5A) and reciprocal co-IP experiments (Supplementary Figure S5B,C), we used mild lysis and wash buffers, slightly modified from a previous study [54]. Mild lysis buffer consisted of $20 \mathrm{mM} \mathrm{K-HEPES} \mathrm{buffer} \mathrm{pH} \mathrm{7.4,} 100 \mathrm{mM} \mathrm{NaOAc}$, $2 \mathrm{mM} \mathrm{MgCl} 2,0.1 \%(v / v)$ Tween 20, $250 \mathrm{mM} \mathrm{NaCl}, 0.5 \%(v / v)$ Triton X-100, $4 \mu \mathrm{g} / \mathrm{mL}$ DNase I (QIAgen, Hilden, Germany), $2 \mu \mathrm{g} / \mathrm{mL}$ RNase A (QIAgen), 1/200 (v/v) each phosphatase inhibitor cocktails 2 and 3 (Sigma-Aldrich), and 1/100 (v/v) protease inhibitor mixture (Sigma-Aldrich). We incubated cleared 
cell lysate with $1-2 \mu \mathrm{g}$ of primary antibody, rotated the mixture at $4{ }^{\circ} \mathrm{C}$ for $2-4 \mathrm{~h}$, and then added 40 $\mu \mathrm{L}$ of Protein A/G PLUS-Agarose beads (Santa Cruz Biotechnology), and rocked at $4{ }^{\circ} \mathrm{C}$ overnight. Wash buffer consisted of $20 \mathrm{mM}$ K-HEPES pH 7.4, $100 \mathrm{mM} \mathrm{NaOAc}, 2 \mathrm{mM} \mathrm{MgCl} 2,0.1 \%(v / v)$ Tween 20, $500 \mathrm{mM} \mathrm{NaCl}$, and $0.5 \%(v / v)$ Triton X-100. We washed bead-antibody complexes four times with wash buffer, twice with PBS, and eluted proteins as described above.

\subsection{BRET NP Oligomerization Assay}

We grew cells to near confluency, harvested by trypsinization, reverse-transfected, and plated cells in poly-D-lysine-coated, 96-well black/clear flat-bottom plates (Corning, Corning, NY, USA). We reverse-transfected cells in each well with $10 \mathrm{ng}$ of pGL4.23-CMV/NP-NLuc or pNL1.1/NLuc (Promega) negative control and $100 \mathrm{ng}$ of pGL4.23-CMV/NP-HaloTag or pcDNA3.3/eGFP negative control. At the start of transfection, we also added HaloTag NanoBRET 618 ligand (NanoBRET Nano-Glo Detection System, Promega) diluted in dimethylsulfoxide (DMSO) at a final concentration of $100 \mathrm{nM}$ or DMSO vehicle control (no HaloTag ligand) to cell culture media.

At $24 \mathrm{~h}$ post-transfection, we added 1:100 NanoBRET Nano-Glo Substrate, incubated cells in the dark at room temperature for $45 \mathrm{~min}$, and measured luminescence on a DTX880 Multimode Detector (Beckman Coulter, Brea, CA, USA) with emission filters of 625/35 nm (HaloTag ligand acceptor signal), and then $465 / 35 \mathrm{~nm}$ (NLuc donor signal), both over 1-second (s) integrations. We calculated BRET signal as the $625 \mathrm{~nm} / 465 \mathrm{~nm}$ ratio with HaloTag ligand, subtracted by the same ratio for the corresponding DMSO vehicle control, as per the manufacturer's protocol.

As a pilot experiment (Figure 3B), we reverse-transfected cells in each well with $10 \mathrm{ng}$ of pGL4.23-CMV/NP-NLuc and 100 ng of pGL4.23-CMV/NP-HaloTag.

For the VP35 inhibition experiment (Figure 3C), we reverse-transfected cells in each well with $2 \mathrm{ng}$ of pGL4.23-CMV/NP-NLuc and 10 ng of pGL4.23-CMV/NP-HaloTag. To test a range of VP35[NPBP] expression, we co-transfected cells with $0,7.5,30$, or $120 \mathrm{ng}$ of pcDNA3.3-WPRE/eGFP-P2A-VP35[NPBP] plasmid. To ensure that cells in each well received the same total amount of DNA, we serially diluted pcDNA3.3-WPRE/eGFP-P2A-VP35(NPBP) in control plasmid pcDNA3.3-WPRE/mTagBFP2, as described in the manufacturer's protocol. We performed the remainder of the standard BRET protocol as described above.

For the donor saturation procedure (Figure 3D), we reverse-transfected cells in each well with $2 \mathrm{ng}$ of pGL4.23-CMV/NP-NLuc. To test a range of NP-HaloTag expression, we co-transfected cells with decreasing amounts $(160,40,10,0 \mathrm{ng})$ of pGL4.23-CMV/NP-HaloTag or pcDNA3.3/eGFP negative control. To ensure that cells in each well received the same total amount of DNA, we serially diluted pGL4.23-CMV/NP-HaloTag or pcDNA3.3/eGFP in control pcDNA3.3/eGFP plasmid, as described in the manufacturer's protocol.

\subsection{Virion-Like Particle Budding Assay}

We grew cells to near confluency, harvested by trypsinization, reverse-transfected, and plated cells in 6-well poly-D-lysine-coated plates (Corning). We reverse-transfected cells in each well with 50 ng of pcDNA3.1/NLuc-VP40 or pNL1.1/NLuc negative control and 2000 ng of pGL4.23-CMV/NP-V5, NP mutants, or pcDNA3.3/eGFP negative control.

At $16 \mathrm{~h}$ post-transfection, we removed supernatant, washed the cells with DMEM, and added $1.5 \mathrm{~mL}$ of fresh DMEM. At $40 \mathrm{~h}$ post-transfection ( $24 \mathrm{~h}$ later), we filtered culture supernatant through an Acrodisc $0.45 \mu \mathrm{m}$ low protein-binding filter (Pall Laboratory, Port Washington, NY). We underlaid $1 \mathrm{~mL}$ of filtered supernatant with $1 \mathrm{~mL}$ of $20 \%(w / v)$ sucrose (Sigma-Aldrich) in PBS and ultracentrifuged at $222,000 \times \mathrm{g}$ at $4{ }^{\circ} \mathrm{C}$ for $2 \mathrm{~h}$. We aspirated the supernatant, resuspended the VLP-containing pellet in 170 $\mu \mathrm{L}$ of PBS, and rocked at room temperature for $1 \mathrm{~h}$. We aliquoted resuspended VLPs into $3 \times 50 \mu \mathrm{L}$ as technical triplicates, added $50 \mu \mathrm{L}$ of Nano-Glo assay reagent (Promega) to each, and incubated in 96-well non-binding-surface plates (Corning) in the dark at room temperature for $10 \mathrm{~min}$. We measured 
total luminescence on a SpectraMax L (Molecular Devices, Sunnyvale, CA, USA) over a 1-s integration. Technical triplicates were averaged and considered as a single biological replicate.

For the thermal stability assay, we reverse transfected cells in each well with $50 \mathrm{ng}$ of pcDNA3.1/NLuc-VP40 per well as above. After filtration, we heated $1.2 \mathrm{~mL}$ of filtered supernatant at 4, 22, 37.1, 43.8, 60.2, or $95^{\circ} \mathrm{C}$, for $30 \mathrm{~min}$ on a Mastercycler pro $\mathrm{S}$ thermocycler (Eppendorf, Hamburg, Germany). We saved $50 \mu \mathrm{L}$ of heated supernatant for direct NLuc measurement. Subsequently, we performed the remainder of the protocol described above (ultracentrifugation of $1 \mathrm{~mL}$ of heated supernatant through sucrose to purify VLPs, and subsequent measurement of NLuc activity).

\subsection{Electron Microscopy}

We seeded $6 \times 10^{5}$ HEK 293 cells per well in 6-well plates. The following day, we transfected cells in each well with $1250 \mathrm{ng}$ of pcDNA3.1(+)-VP40 (untagged), $930 \mathrm{ng}$ of pGL4.23-CMV/NP or pGL4.23-CMV/NP-R111C (both untagged), and $310 \mathrm{ng}$ of pGL4.23-CMV/GP-A82V [15] using $6.25 \mu \mathrm{L}$ of TransIT-LT1 Transfection Reagent (Mirus Bio). We changed media the next morning. After $48 \mathrm{~h}$, we filtered culture supernatant through a $0.45 \mu \mathrm{m}$ filter and overlaid it onto a $20 \%(w / v)$ sucrose in TNE (10 mM Tris-Cl, $100 \mathrm{mM} \mathrm{NaCl}, 1 \mathrm{mM}$ EDTA $\mathrm{pH}$ 7.5) cushion. VLPs were pelleted by ultracentrifugation at $222,000 \times g$ at $4{ }^{\circ} \mathrm{C}$ for $2 \mathrm{~h}$. We aspirated the supernatant, washed the VLP-containing pellet gently with $1 \mathrm{~mL}$ of ice-cold PBS, resuspended VLPs in $100 \mu \mathrm{L}$ of $2 \%$ FBS in PBS, and stored VLPs at $4{ }^{\circ} \mathrm{C}$ prior to EM.

We prepared samples for EM based on a previously described protocol [55]. Briefly, we performed all spreads onto freshly prepared carbon-stabilized Formvar support films on 200 mesh copper grids. We adsorbed VLPs onto a carbon-coated Formvar support films for $30 \mathrm{~s}$. We removed excess liquid with filter paper, and negatively stained the samples immediately by running 6 drops of $1 \%$ uranyl acetate over the grid for contrast. We removed excess stain and air-dried the samples in a controlled humidity chamber. We then examined the samples using a FEI Tecnai 12 Spirit BioTwin transmission electron microscope (Thermo Fisher Scientific) using an accelerating voltage of $120 \mathrm{kV}$. We captured micrographs at various magnifications to record the fine structure of VLPs and exported micrographs into ImageJ [56] to measure the length and volume of individual particles.

\subsection{Monocistronic Minigenome Assay}

Monocistronic (1MG) minigenome plasmids and procedure were previously described [52]. We seeded HEK $293 \mathrm{~T}$ cells into 12-well plates, grew to $70 \%$ confluency, and transfected cells in each well with $2 \mu \mathrm{g}$ of pCAGGS/L, $0.25 \mu \mathrm{g}$ of pCAGGS/VP30, $0.5 \mu \mathrm{g}$ of pCAGGS/T7 RNA polymerase (T7pol), $0.5 \mu \mathrm{g}$ of $1 \mathrm{MG}$ plasmid encoding FLuc, $0.1 \mu \mathrm{g}$ of pCAGGS encoding RLuc, and $0.75 \mu \mathrm{g}$ of pCAGGS/NP-2A-VP35 for each NP mutant. After 2 days, we washed and lysed cells with $100 \mu \mathrm{L}$ of 1X Passive Lysis Buffer (Dual Luciferase Assay Kit, Promega), freeze-thawed lysates, and cleared by centrifugation. We incubated $10 \mu \mathrm{L}$ of lysate with $50 \mu \mathrm{L}$ of Luciferase Assay Reagent II, let the mixture settle for $2 \mathrm{~s}$, and integrated luminescence for $10 \mathrm{~s}$ on a Spark 10M microplate reader (Tecan, Zürich, Switzerland) to measure FLuc activity. We then added $50 \mu \mathrm{L}$ of Stop \& Glo reagent and integrated luminescence for $10 \mathrm{~s}$ to measure RLuc activity.

\subsection{Tetracistronic Minigenome Assay}

We followed an existing protocol for the tetracistronic (4MG) minigenome assay [57], with some modifications. We first generated transcription- and replication-competent (tr)VLPs using HEK 293T as producer (P0) cells. We seeded HEK 293T cells into collagen-coated 6-well plates, grew to $40 \%$ confluency, and transfected cells in each well with the previously described plasmid ratio (125 ng of pCAGGS/NP, $125 \mathrm{ng}$ of pCAGGS/VP35, $75 \mathrm{ng}$ of pCAGGS/VP30, $1000 \mathrm{ng}$ of pCAGGS/L, $250 \mathrm{ng}$ of 4MG plasmid encoding RLuc, 250 of ng pCAGGS/T7pol) [57,58], plus $250 \mathrm{ng}$ of a FLuc-encoding plasmid to normalize for transfection efficiency. We changed media $24 \mathrm{~h}$ post-transfection, collected and clarified 
trVLP-containing P0 supernatant by centrifugation, and measured intracellular luminescence in P0 cells $96 \mathrm{~h}$ post-transfection.

We used trVLP-containing supernatant to infect target Huh7 cells for a total of two trVLP passages (P1 and P2 cells). We seeded Huh7 cells into collagen-coated 6-well plates as P1 cells, grew to $40 \%$ confluency, and transfected cells in each well with the plasmid ratio above except without the 4MG plasmid or the pCAGGS/T7pol [57,58]. We inoculated P1 cells with $3 \mathrm{~mL}$ of trVLP-containing P0 supernatant $24 \mathrm{~h}$ post-transfection, changed media $24 \mathrm{~h}$ post-inoculation, and measured luminescence in P1 cells and collected trVLP-containing P1 supernatant $96 \mathrm{~h}$ post-inoculation. We performed the procedure again by transfecting fresh Huh7 cells, inoculating these P2 cells with P1 trVLPs, and measuring luminescence.

To measure intracellular luminescence in P0, P1, and P2 cells, we lysed cells with $500 \mu \mathrm{L} 1 \mathrm{X}$ Passive Lysis Buffer (Dual Luciferase Assay Kit, Promega) at room temperature for $15 \mathrm{~min}$, freeze-thawed lysates, and detected FLuc and RLuc luminescence with the Dual Luciferase Assay Kit as described above.

\subsection{Tandem Mass Spectrometry}

To assess protein-protein interactions of NP (Supplementary Figure S5), we scaled up our co-IP protocol. We grew two $15 \mathrm{~cm}^{2}$ plates of cells to $40-60 \%$ confluency and transfected cells with $32 \mu \mathrm{g}$ of pGL4.23-CMV/NP-myc encoding either NP-R111 or NP-K109E/K110E/R111E. After 48 h, we harvested cells by scraping in 1.2\% (w/v) polyvinylpyrrolidine (PVP) in $20 \mathrm{mM} \mathrm{K-HEPES} \mathrm{buffer} \mathrm{pH} 7.4$, snap-froze with liquid nitrogen, and then lysed in $2.5 \mathrm{~mL}$ of mild lysis buffer, as described above.

We performed co-IP of myc-tagged NP complexes using $25 \mu \mathrm{g}$ of mouse $\alpha$-myc IgG or irrelevant normal mouse IgG at $4{ }^{\circ} \mathrm{C}$ overnight, and bound complexes to $250 \mu \mathrm{L}$ of Protein A/G PLUS-Agarose beads at $4{ }^{\circ} \mathrm{C}$ for $2 \mathrm{~h}$. We washed beads as described above and eluted proteins in $120 \mu \mathrm{L}$ of Laemmli sample buffer at $95^{\circ} \mathrm{C}$ for $10 \mathrm{~min}$. We separated proteins on denaturing PAGE gels, visualized with PageBlue Protein Staining Solution (Thermo Fisher Scientific), and excised lanes excluding IgG chains.

We cut gel bands into approximately $1-\mathrm{mm}^{3}$ pieces and performed a modified in-gel trypsin digestion procedure [59]. We dehydrated pieces with acetonitrile for $10 \mathrm{~min}$, dried them completely in a speed-vac pump, and rehydrated with $50 \mathrm{mM}$ ammonium bicarbonate solution containing 12.5 $\mathrm{ng} / \mu \mathrm{L}$ of sequencing-grade modified trypsin (Promega) at $4{ }^{\circ} \mathrm{C}$ for $45 \mathrm{~min}$. To extract peptides, we replaced the solution with $50 \mathrm{mM}$ trypsin-free ammonium bicarbonate solution and incubated at $37^{\circ} \mathrm{C}$ overnight. We washed peptides once with $50 \%$ acetonitrile and $1 \%$ formic acid, dried in a speed-vac pump for $\approx 1 \mathrm{~h}$ and then stored at $4{ }^{\circ} \mathrm{C}$. On the day of analysis, we reconstituted peptides in $5-10 \mu \mathrm{L}$ of high-performance liquid chromatography (HPLC) solvent A ( $2.5 \%$ acetonitrile, $0.1 \%$ formic acid). We packed nano-scale reverse-phase HPLC capillary columns with $2.6 \mu \mathrm{m} \mathrm{C18} \mathrm{spherical} \mathrm{silica} \mathrm{beads}$ into fused silica capillary tubes (100 $\mu \mathrm{m}$ inner diameter $\mathrm{x} \approx 25 \mathrm{~cm}$ length) using flame-drawn tips [60]. After equilibrating the columns, we loaded each sample via a Famos autosampler (LC Packings, San Francisco, CA, USA). We eluted peptides with increasing concentrations of solvent B ( $97.5 \%$ acetonitrile, $0.1 \%$ formic acid).

To detect peptides, we performed tandem mass spectrometry (MS/MS) on an LTQ Orbitrap Velos Pro ion-trap mass spectrometer (Thermo Fisher Scientific). We matched MS/MS fragmentation spectra to human forward protein databases and against reverse databases to a $1-2 \%$ false discovery rate using the SEQUEST database search program (Thermo Fisher Scientific) [61]. We computed unique and total peptide spectra matches (PSMs) for each identified protein.

To generate a list of putative NP interacting partners, we filtered proteins with at least 2 unique PSMs in co-IPs of both NP-R111 and NP-K109E/K110E/R111E, and at least 2-fold greater-than-average PSM enrichment of $\alpha$-myc co-IP over both IgG controls combined. To eliminate abundant and 'sticky' proteins, we normalized average PSM enrichment against PSMs identified in all 411 Contaminant Repository for Affinity Purification (CRAPome) version 1.1 experiments [62], a collection of proteins identified in negative control isolations. From each replicate, we used the top $10 \%$ proteins enriched versus CRAPome experiments for Search Tool for the Retrieval of Interacting Genes/proteins (STRING) 
version 10 analysis $[63,64]$ and visualized interactions with Cytoscape [65]. See Supplementary File S2 for raw and filtered peptide/protein PSM counts.

\subsection{Statistical Analysis}

Except where specified, we performed all hypothesis testing using Prism 7 (GraphPad Software, La Jolla, CA, USA) and all non-linear curve fitting using R [66] and the 'nlstools' package [67]. We generated most plots using the 'ggplot2' package in $\mathrm{R}$ [68].

For the VP35 inhibition experiment using BRET (Figure 3C), we expressed varying amounts of VP35[NPBP] in cells in the presence of NP-NLuc and NP-HaloTag for 4 amounts of pcDNA3.3-WPRE/eGFP-P2A-VP35[NPBP] plasmid ( $n=3$ biological replicates each). We fitted the data to an inverse function using the 'nls' function in R:

$$
\text { BRET scale/(VP35[NPBP] + max })+\min ,
$$

in which VP35[NPBP] expression was the independent variable, BRET was the dependent variable, and scale, max, and min were constants to be fitted. Using non-linear regression, we fitted the parameters scale $=1.9 \times 10^{5}, \max =3.4 \times 10^{4}$, and $\min =0.49$. In the absence of VP35 $(\mathrm{VP} 35[\mathrm{NPBP}]=0)$, the maximum BRET signal would be 5.80; with very high expression (VP35[NPBP] $\rightarrow \infty$ ), the minimum BRET signal would be 0.49 . We used the 'nlstools' package to generate 999 bootstrap pseudoreplicates, inferred parameters for each pseudoreplicate, and plotted the central $95 \%$ of values as a shaded region.

For donor saturation assay using BRET (Figure 3D), we performed the BRET protocol with NLuc- and HaloTag-tagged NP-R111 or NP mutants or eGFP control for 4 amounts of pGL4.23-CMV/NP-HaloTag plasmid ( $n=6$ biological replicates each). We fitted the data to saturation curves using the 'nls' function in R:

$$
\text { BRET Max * NP-HaloTag/(BRET } 50+\text { NP-HaloTag), }
$$

in which the amount of NP-HaloTag plasmid was the independent variable, BRET was the dependent variable, and Max and BRET $_{50}$ were constants to be fitted. For NP-R111 or each NP mutant or eGFP control, we estimated Max and $\mathrm{BRET}_{50}$ and generated $95 \%$ confidence intervals using 'nlstools' as described above. Data points from eGFP failed to generate an appropriate curve fit. To determine whether the remaining curve fits were significantly different from each other, we performed analysis of variance (ANOVA) with Dunnett's post-test in which NP-R111C, NP-R111E, and NP-K109E/K110E/R111E were compared to NP-R111, and generated multiple hypothesis corrected $p$-values using Prism 7.

To measure VLP production from NLuc-VP40, NLuc-VP40-L117R, or NLuc alone (Figure 4B), we quantified raw NLuc intensities ( $n=6$ biological replicates each). To assess statistical significance, we performed a repeated measures ANOVA (rANOVA) with Dunnett's post-test, in which each condition was compared to NLuc-VP40 to generate corrected $p$-values using Prism 7.

To measure the impact of NP genotype on VLP production (Figure 4C), we co-expressed NLuc-VP40 and NP-R111 or NP mutants (R111C, R111E, K109E/K110E/R111E, $\Delta$ C50-a 50 amino acid truncation of the NP C-terminus [35]) or eGFP control. rANOVA revealed significant day-to-day (replicate-to-replicate) variability, so we normalized all NLuc intensities within each replicate to each replicate's NP-R111 value. We performed Dunnett's post-test with the NP-R111 group removed (since variance and degrees of freedom of NP-R111 are both 0 after normalization) and compared each NP mutant or eGFP versus 1 to generate corrected $p$-values using the 'ncDunnett' package in R [69].

To determine whether heating disrupted VLPs (Supplementary Figure S3B), we expressed NLuc-VP40 in cells, and heated cell culture supernatant to $4,22,37.1,43.8,60.2$, or $95^{\circ} \mathrm{C}$ either before or after purifying VLPs via ultracentrifugation ( $n=3$ biological replicates in a repeated-measures design). 
We normalized NLuc values for all temperatures to the $4{ }^{\circ} \mathrm{C}$ value for each replicate, $\log$-transformed the normalized values, and fitted the data to sigmoidal curves using the 'nls' function in R:

$$
\log _{10}(\text { NLuc.Norm }) \sim \min +\max /\left(1+e^{(\text {midpt }- \text { temp })} / \text { scale }\right),
$$

in which temperature was the independent variable, NLuc.Norm was the dependent variable, and min, max, midpt, and scale were all constants to be fitted. Additionally, we tested whether NLuc luminescence differed following heating the supernatant to $60.2{ }^{\circ} \mathrm{C}$ either before or after purifying VLPs with a paired $t$-test using Prism 7.

To measure the impact of NP genotype on $1 \mathrm{MG}$ minigenome activity (Figure 5B), we expressed NP-R111 or NP mutants with the rest of the EBOV replication complex (VP35, VP30, L), the FLuc-encoding 1MG minigenome, and an RLuc-encoding plasmid to control for transfection efficiency ( $n=3$ biological replicates each). We normalized FLuc by RLuc luminescence for each replicate, then normalized all values to the average FLuc/RLuc ratio of the NP-R111 replicates. We performed ANOVA with Dunnett's post-test, in which each condition was compared to NP-R111 to generate corrected $p$-values using Prism 7.

To measure the impact of NP genotype on $4 \mathrm{MG}$ minigenome activity (Figure 5C), we expressed NP-R111 or NP mutants with the rest of the EBOV replication complex, the RLuc-encoding 4MG minigenome, and an FLuc-encoding plasmid to control for transfection efficiency $(n=3-9$ biological replicates each). Due to significant day-to-day (replicate-to-replicate) variability, we normalized RLuc by FLuc luminescence for each replicate, then normalized all values to the average RLuc/FLuc ratio of the GP-A82/NP-R111 replicates prepared on that day. We performed ANOVA with Tukey's post-test, in which each condition was compared to each other condition to generate corrected $p$-values using Prism 7. To measure the change in minigenome activity between passages (Figure 5D), we passaged cell culture supernatant from P0 to P1, and then from P1 to P2 cells, keeping track of each replicate. We normalized P1 and P2 RLuc/FLuc values to their own P0 replicate, and then normalized all values to the average value of the GP-A82/NP-R111 replicates prepared on that day. We assessed statistical significance using ANOVA with Tukey's post-test to generate corrected $p$-values using Prism 7.

\section{Results}

\subsection{EBOV NP-R111C Emerged alongside the GP-A82V Substitution during the 2013-2016 Western African Epidemic}

Among the viral mutations that rose to dominate the EBOV population during the 2013-2016 Western African EVD epidemic, the NP-R111C substitution is of great interest because it shares features with the GP-A82V substitution that enhanced viral infectivity in vitro [15-20]. GP-A82V and NP-R111C were two major clade-defining substitutions that rose to high frequency during the epidemic; other mutations did not affect the amino acid sequence of EBOV proteins [4,8]. Based on phylogeny of EBOV genomes from clinical samples, the NP-R111C substitution (Figure 1A, blue) occurred soon after the emergence of GP-A82V (Figure 1A, green) and temporally preceded the inflection point of the epidemic (Figure 1B). Indeed, few EBOV Makona variant genomes encoded GP-A82V in the absence of NP-R111C (23 cases, $1.26 \%$ of total), and the overwhelming majority of genomes encoded both substitutions (1653 cases, $90.67 \%$ of total).

\subsection{The EBOV NP-R111 Residue Lies outside Known Functional Regions of NP, but Could Impact $N P-N P$ Interaction}

To investigate the functional importance of the NP-R111 residue, we examined existing annotations and functions of NP. The NP-R111 residue lies outside of key sites known to interact with EBOV RNA and VP35 (Figure 2A). Moreover, in NP crystal structures [23,25], the R111 residue appeared on the same face of the protein as the NP oligomerization domain (Figure 2B, left), opposite the key VP35 and RNA interaction residues (Figure 2B, right). Electron microscopy (EM) subtomogram averaging 
indicated that R111 is proximally located to key NP oligomerization residues [26]. Interestingly, R111 lies amidst a conserved stretch of 3 basic residues, K109, K110, and R111, on the surface of the NP protein (Figure 2C, yellow). Recent cryo-EM structures identified K110, adjacent to R111, as a residue forming a key electrostatic interstrand NP-NP interaction $[28,29]$ that is highly conserved (Figure 2C). Indeed, deuterium exchange mass spectrometry indicated that K110 and R111 residues were partially buried in wild-type NP compared to an oligomerization-incompetent NP [27]. Therefore, we focused on whether NP-R111C affects oligomerization during the EBOV life cycle, and further queried this residue by generating charge-reversed mutants (NP-R111E and NP-K109E/K110E/R111E).

\subsection{EBOV NP Position 111 Significantly Affects Oligomerization of NP}

To address whether substitution at NP-R111 could influence NP-NP interaction and thereby NP oligomerization, we developed an assay to measure intracellular NP oligomerization using bioluminescence resonance energy transfer (BRET). Traditional oligomerization assays in cell culture involve tagging a protein separately with two different tags, co-expressing both tagged proteins, and then targeting one tag with co-immunoprecipitation (co-IP) and detecting the other tag by Western blot (WB) $[53,70,71]$. However, WB often has linear dynamic range issues; furthermore, co-IPs can introduce non-specific or spurious protein-protein interactions using different cell lysis and binding buffers. To overcome these deficits of co-IPs and WBs, we used BRET to study NP oligomerization in live cells. We tagged the NP C-terminus with either the chemiluminescent enzyme NanoLuc (NLuc) or the HaloTag protein (which covalently binds to an acceptor fluorophore). We co-expressed both tagged NPs in cells, and activated NP-NLuc with substrate, resulting in emission of light at $465 \mathrm{~nm}$. Spatial proximity of NP-NLuc to NP-HaloTag due to NP oligomerization results in energy transfer and a second light emission at a longer wavelength, $625 \mathrm{~nm}$ (Figure 3A) [72].

To verify that our assay was truly measuring NP oligomerization, we generated a loss-of-function (LOF) mutant and disrupted oligomerization with EBOV VP35. We generated NP- $\triangle O D$ (deletion of oligomerization domain, NP residues 20-38), a LOF mutant that biochemical methods (size exclusion chromatography and multiangle light scattering) indicated to be defective in oligomerization [25]. To replicate these previous results in cell culture, we expressed V5- and myc-tagged NP- $\Delta$ OD in cells and confirmed that NP- $\triangle \mathrm{OD}$ lacked oligomerization capability using the traditional dual-tag co-IP-WB strategy (Supplementary Figure S1). We then generated NLuc- and HaloTag-tagged NP and NP- $\triangle \mathrm{OD}$ and performed our BRET assay in live cells. As expected, expression of NP-NLuc and NP-HaloTag resulted in bright BRET luminescence, compared to the tagged versions of NP- $\triangle \mathrm{OD}$ which only resulted in low background signal (Figure 3B). This background signal persisted in the presence of NP-HaloTag without NP-NLuc or with NP-HaloTag and free NLuc (not fused to NP), but was absent when NP-NLuc was expressed without NP-HaloTag, suggesting that the background signal was due to autoluminesence of the HaloTag ligand and not oligomerization of NP- $\Delta$ OD (Figure $3 \mathrm{~B}$ ). To confirm our assay in a biologically relevant context, we expressed the NP-binding peptide (NPBP) of EBOV VP35 in cells, which is known to disrupt NP oligomerization [24,25]. To quantitatively detect VP35[NPBP] expression, we fused enhanced green fluorescent protein (eGFP) to NPBP via a bridging porcine teschovirus $12 \mathrm{~A}$ 'self-cleaving' peptide [48] (eGFP-P2A-VP35[NPBP]) and co-transfected varying amounts of this plasmid. Increasing expression of eGFP-P2A-VP35[NPBP] led to a quantitative decrease in BRET oligomerization signal, fitting well to an inverse function (Figure 3C, Equation (1)).

Next, we measured the propensity of NP-R111 mutants to oligomerize and found that NP-R111C, and to an even greater extent NP-R111E and NP-K109E/K110E/R111E, increased NP oligomerization. To quantify oligomerization, we expressed increasing amounts of acceptor NP-HaloTag in cells to saturate the donor NP-NLuc signal. The resulting oligomerization curves fit well to saturation curves, parameterized by Max (maximum oligomerization) and BRET 50 (ratio of NP-HaloTag:NP-NLuc plasmid needed to reach half Max) (Figure 3D, Equation (2)) [73]. As expected, control eGFP substituted for NP-NLuc (black dots) did not generate detectable BRET signal, and NP- $\triangle \mathrm{OD}$ (gray) resulted in background signal at high concentrations, common among BRET assays [74]. Relative to NP-R111 (tan), 
NP-R111C (red) slightly, but not statistically significantly, increased oligomerization (12\% lower BRET 50 ; $p<0.74$, ANOVA with Dunnett's test to correct for multiple hypotheses), whereas the charge-reversed NP-R111E (light blue; 36\% lower BRET $50 ; p<0.031$, ANOVA-Dunnett's test) oligomerized at even lower NP concentrations (Figure 3D). The triple charge-reversed NP-K109E/K110E/R111E oligomerized at similarly low NP concentrations (dark blue; $28 \%$ lower BRET $_{50}$ than NP-R111). Though this difference in $\operatorname{BRET}_{50}(p<0.11$, ANOVA-Dunnett's test) failed to reach traditional statistical significance cut-offs, NP-K109E/K110E/R111E produced significantly higher mean BRET signal than NP-R111 when the ratio of NP-HaloTag to NP-NLuc was 5 ( $p<0.0003$; ANOVA-Dunnett's test) or 20 ( $p<0.0007$; ANOVA-Dunnett's test), and its biochemical similarity to NP-R111E further suggested that its increased oligomerization was meaningful. We verified that different NP variants were expressed at similar concentrations by comparing the luminescence of NP-NLuc mutants in the absence of the HaloTag substrate (Supplementary Figure S2). These results support our hypothesis that the NP 111 allele affects the K110-E349 NP-NP interaction (Figure 2C) suggested by cryo-EM [28,29].

\subsection{EBOV NP-R111C Increases Budding of Virion-Like Particles}

To determine whether the different mutants impact NP's role in virion structure, we designed and optimized a VLP budding assay. Traditionally, researchers assess viral budding efficiency by harvesting cell culture supernatants, purifying VLPs by ultracentrifugation through sucrose, and detecting VLPs by WB using antibodies to specific VLP components $[35,51,75,76]$. However, WBs are often insensitive to modest changes in VLP numbers and can suffer from high technical variability. By contrast, luminescence can be reproducibly detected over a larger linear dynamic range. However, the size of firefly luciferase (FLuc; $60 \mathrm{kDa}$ ) can severely interfere with incorporation into budding VLPs. Indeed, although the EBOV matrix protein VP40 (40 kDa) alone is sufficient to bud VLPs [32-34], fusion of VP40 to FLuc decreased luciferase activity to undetectable levels in a budding assay [75]. Here, we took advantage of the smaller size of NLuc (19 kDa) [77] and fused it to VP40. We expressed NLuc-VP40 in cells, purified VLPs following established protocols, and measured NLuc reporter activity (Figure $4 \mathrm{~A}$ ).

One major challenge to VLP budding assays is that VP40 can be expelled from cells as a monomer [78] perhaps via exosomes [79]. To distinguish between monomeric VP40 and VLPs, we used a LOF mutant, VP40-L117R, which is defective in VLP budding as judged by immunofluorescence microscopy and WB [51]. We expressed NLuc-VP40 or NLuc-(VP40-L117R) in cells and collected unpurified supernatant or purified VLPs by ultracentrifugation through a $20 \%(w / v)$ sucrose cushion. We added NLuc substrate and measured luminescence in unpurified supernatant or the VLP-containing pellet. As expected, budding of VLPs containing NLuc-(VP40-L117R) LOF mutant was impaired by $>400$-fold compared to NLuc-VP40 ( $p<0.001$; paired $t$-test) (Figure $4 \mathrm{~B}$ ). We did not observe as large of a difference between NLuc-VP40 and NLuc-(VP40-L117R) in unpurified culture supernatant (Supplementary Figure S3A, left), suggesting that an appreciable amount of monomeric VP40 was secreted from cells. Moreover, treating cells with brefeldin A, an inhibitor of coat protein complex I (COPI)-mediated transport, did not affect luminescence in unpurified supernatant (Supplementary Figure S3A), suggesting that secretion of monomeric VP40 was independent of this major transport mechanism, as reported previously [78]. To further verify that we were measuring luminescence from VLPs rather than monomeric VP40, we heated culture supernatant prior to ultracentrifugation. If VLPs were present, heating would dissociate VLPs into VP40 monomers [80], which would fail to pellet after ultracentrifugation through sucrose. Whereas heating supernatant to $60.2{ }^{\circ} \mathrm{C}$ decreased NLuc activity [77], heating and subsequent ultracentrifugation reduced NLuc activity an additional 15 -fold ( $p<0.007$; paired $t$-test), suggesting that NLuc-VP40 VLPs were denatured and, thus, were not pelleted and detected (Supplementary Figure S3B).

We then further optimized our VLP assay to maximize the difference between NLuc-VP40 and the LOF mutant NLuc-(VP40-L117R). We first transfected cells with a range of NLuc-VP40 or NLuc-(VP40-L117R) plasmid amounts and measured luminescence in unpurified culture supernatant. 
A relatively small amount of NLuc-VP40 plasmid (2.22 ng) produced the greatest difference in luminescence between NLuc-VP40 and NLuc-(VP40-L117R) (Supplementary Figure S3C). Though NLuc is a relatively small protein $(19 \mathrm{kDa})$, fusion to VP40 (40 kDa) could still impair VP40 interactions and functions. Co-expressing increasing amounts of 'dark' untagged VP40 in cells did not increase the difference in luminescence between wild-type NLuc-VP40 and LOF mutant (Supplementary Figure S3D), suggesting that the NLuc tag did not drastically interfere with VLP production. Lastly, we optimized the amount of NP plasmid to co-transfect with NLuc-VP40, and, consistent with NP's role in promoting VLP formation, increasing the amount of NP plasmid transfected always increased luminescence and resulted in greater difference in luminescence between NLuc-VP40 and NLuc-(VP40-L117R) (Supplementary Figure S3E).

Finally, we tested how different NP mutants affected our VLP budding assay and found that only NP-R111C affected VLP production. Expression of viral nucleoproteins, including EBOV $\mathrm{NP}$, is known to significantly increase matrix protein-induced VLP production [35]. We verified that ancestral NP-R111 (tan) increased NLuc-VP40 VLP production 1.93-fold compared to eGFP control (gray; $p<0.0002$, repeated measures ANOVA with Dunnet's test to correct for multiple hypothesis testing) (Figure 4C). NP-R111C (red) significantly increased VLP production above NP-R111 (1.26-fold; $p<0.039$, rANOVA-Dunnett's test), whereas the charge-reversed NP-R111E (light blue; 1.07-fold; $p<0.847$, rANOVA-Dunnett's test) and NP-K109E/K110E/R111E (dark blue; 1.13-fold; $p<0.484$, rANOVA-Dunnett's test) did not have reproducible effects. To determine whether increased luminescence was due to increased VLP size, we expressed unfused VP40, GP, and NP-R111 or NP-R111C, and visualized VLPs via EM (Supplementary Figure S4A). However, we did not detect any changes in length or volume of VLPs due to NP-R111C substitution (Supplementary Figure S4B).

\subsection{EBOV NP Position 111 Influences Viral Transcription and Replication}

The mechanism by which changes in NP's structural phenotypes (e.g., oligomerization, budding) affect viral transcription and replication is not obvious because NP is highly multi-functional. NP's ability to oligomerize can influence its ability to bind RNA and modulate transcription and replication, though the direction and size of this effect are not always clear $[24,25,27]$. We quantified viral transcription and replication using two minigenome reporter assays (Figure 5A) [52,57]. In each assay, we expressed the components of the EBOV ribonucleoprotein (RNP) complex (NP, VP35, VP30, and $\mathrm{L}$ ) in cells in the presence of a minigenome encoding a luciferase reporter flanked by the EBOV promoter-like leader and trailer sequences. Transcription is essential for minimal luciferase activity; replication is further required to achieve maximum signal [81]. Whereas the first reporter system uses a monocistronic minigenome (1MG) to assess only transcription and replication [52], the second system uses a tetracistronic minigenome (4MG) to produce transcription- and replication-competent VLPs (trVLPs) (Figure 5A). These 4MG trVLPs can be further 'passaged' as a measure of ability to infect target cells and complete the viral life cycle [57]. As a positive control, we further tested the $4 \mathrm{MG}$ system in the presence of the GP-A82V mutation, which increases viral infectivity in cell culture [15-20].

Using the $1 \mathrm{MG}$ system, only the charge-reversal NP mutants affected transcription and replication differently than the wild-type. As expected, the absence of EBOV VP30, L, or the minigenome (gray) resulted in $<5 \%$ normalized minigenome activity compared to cells expressing the minigenome and the entire RNP complex with NP-R111 (tan, Figure 5B). Substitution of NP-R111C (red) in place of NP-R111 yielded similar activity (99\%). On the other hand, the charge-reversal mutants NP-R111E (light blue; 23\% reporter activity; $p<0.003$; ANOVA-Dunnett's test) and NP-K109E/K110E/R111E (dark blue; $44 \%$ activity; $p<0.017$; ANOVA-Dunnett's test) greatly attenuated transcription and replication.

In the 4MG trVLP system, we again observed that NP-R111E abrogated transcription and replication in the producer (P0) cells, though NP-R111C modestly decreased activity as well. As expected, we detected virtually no signal from any cells in the absence of EBOV L (gray). Paired with the ancestral GP-A82 (Figure 5C, left), NP-R111E (light blue) dramatically reduced reporter activity compared to NP-R111 (tan; 33\% activity; $p<0.0001$, ANOVA-Tukey's test to correct for 
multiple hypothesis testing), and NP-R111C (red) modestly decreased activity as well (80\% activity; $p<0.0001$, ANOVA-Tukey's test). Because the P0 cells are transfected with plasmid encoding the 4MG minigenome, these cells primarily account for transcription and replication without the requirement for trVLP entry and spread; therefore, we do not expect the GP-A82V substitution, which only increases viral entry [15-20], to dramatically affect transcription and replication in P0 cells. Indeed, compared to GP-A82, GP-A82V did not measurably increase reporter activity in the context of NP-R111 (tan, left vs. right; $102 \%$ activity; $p<0.96$, ANOVA-Tukey's test), and marginally enhanced the activity of NP-R111C (red, left vs. right; $80 \%$ to 90\% activity; $p<0.006$, ANOVA-Tukey's test) but not NP-R111E (light blue, left vs. right; 33\% to 35\% activity; $p<0.998$, ANOVA-Tukey's test, Figure 5C).

We used trVLP-containing culture supernatant from $\mathrm{P} 0$ cells to inoculate a first round of target cells (P1), and repeated the procedure using P1 trVLPs to inoculate a second round of target cells (P2). $\mathrm{P} 1$ and P2 cells were not transfected with plasmid encoding 4MG; instead, these cells contained 4MG minigenome if and only if a trVLP entered the cell. Since P1 and P2 minigenome activity depended on transcription, replication, and viral entry and spread, we calculated fold-change in reporter gene activity relative to P0 (Figure 5D). In the presence of ancestral GP-A82, NP-R111C (solid red lines) modestly decreased reporter activity compared to NP-R111 in P1 (solid tan lines; 77\% of fold-change in activity; $p<0.053$, ANOVA-Tukey's test) and further in P2 (59\% of fold-change in activity; $p<0.35$, ANOVA-Tukey's test). NP-R111E (solid blue lines) appeared completely unable to spread in P1 (1\% of fold-change in activity; $p<0.0001$, ANOVA-Tukey's test) and P2 ( $0.05 \%$ of fold-change in activity; $p<0.0003$, ANOVA-Tukey's test) cells. As expected, GP-A82V (dashed lines) spread much better than ancestral GP-A82 (solid lines) in the context of NP-R111 (tan; P1: 137\% of fold-change in activity, $p<0.0001$, ANOVA-Tukey's test; P2: 218\% of fold-change in activity, $p<0.0001$, ANOVA-Tukey's test) and NP-R111C (red; P1: 77\% to 104\% of fold-change in activity, $p<0.014$; P2: $59 \%$ to $67 \%$ of fold-change in activity, $p<0.999$ ), though NP-R111E was completely defective regardless of GP-82 allele (dashed and solid light blue lines overlap along the $x$-axis).

\subsection{Probing EBOV NP's Interactome Reveals Interaction with the AP-1 Clathrin Adaptor Complex}

We wanted to further explore why the charge-reversal mutants were strikingly defective at viral transcription and replication, and considered that charge-reversal might alter NP's protein-protein interactions. The binding interfaces of VP30 and VP35 are on the opposite face of NP as the R111 residue (Figure 2B), suggesting that these viral interactions are likely to be unaffected. Only a handful of host interactome studies have been performed on EBOV NP [82-85], all utilizing the NP amino acid sequence from the Mayinga isolate of the EBOV Yambuku variant (EBOV/Yam-May), the first EBOV isolated in 1976. To build upon these previous results, we performed co-immunoprecipitation tandem mass spectrometry (co-IP MS/MS) using myc-tagged NP from EBOV/Makona variant bearing either R111 or K109E/K110E/R111E, which had the most dramatic charge-reversal.

Though we did not detect differential interactions between the two NP genotypes, our approach yielded multiple members of the adaptor related protein 1 (AP-1) complex as strong candidate host protein interactors (Supplementary Figure S5A). Several AP-1 members had been identified previously $[82,83,85]$ but were not further confirmed. The AP-1 complex mediates intracellular transport, and therefore could be important for viral transcription and replication, or VLP formation and budding. Here, we confirmed that both NP-R111 and NP-K109E/K110E/R111E strongly interacted with AP-1 subunit M1 (AP1M1) and AP1G1 by reciprocal IP-WB (Supplementary Figure S5B). Moreover, NP-R111C, NP-R11E, and NP-K109E/K110E/R111E all bound to the AP-1 complex with similar affinity as NP-R111 (Supplementary Figure S5C). These results suggest that, though the AP-1 interaction did not explain differences between the mutants in our assays, the interaction could play a role in NP function. 


\section{Discussion}

Here, we developed and modified BSL-2 assays to study in-depth a key EBOV NP substitution, NP-R111C, which arose during the 2013-2016 Western African EVD epidemic. Though the NP-R111 residue has not been previously annotated as functional, the residue's proximity to a key NP-NP electrostatic interaction led us to consider that substitution at this residue could affect multiple viral phenotypes. Because EBOV NP plays many critical roles during the life cycle, we developed assays for NP oligomerization and VLP budding in live cells with controls. These assays are biologically relevant for EBOV and may also be appropriate for other viral nucleoproteins as well. Our data reveal that NP position 111 is importantly positioned to affect both phenotypes as well as viral transcription and replication. NP-R111, the adjacent basic residues K109 and K110, and the K109-E349 salt bridge identified by cryo-EM [28,29], are highly conserved among ebolaviruses, including in the newly described Bombali virus [86] (Figure 2C). This high degree of conservation, despite significant evolutionary divergence between ebolaviruses, emphasizes the importance of this highly basic region to NP functions.

Charge-reversal at these residues, NP-R111E and NP-K109E/K110E/R111E, produced dramatic phenotypes, including significantly increased BRET signal (Figure 3D), indicating increased oligomerization and/or structural changes that brought the NLuc and HaloTag tags (at the NP C-terminus) into closer proximity. This increase in BRET signal is seemingly paradoxical, since charge-reversal should disrupt the K109-E349 electrostatic interaction between NP monomers. However, even if this interaction is lost, a nearby residue, K352, may be able to stabilize E349, thereby altering the structure of NP oligomers. Computationally modeling how NP-R111E would affect NP oligomer structure is challenging because the interface between the two NP monomers is very hydrophilic and likely filled with water. Generating cryo-EM structures of these mutants may further elucidate the mechanism of NP oligomer self-assembly.

It is intriguing that NP-R111E's increased oligomerization correlated with severely defective minigenome transcription and replication (Figure 5B,C), to the degree that NP-R111E trVLPs were unable to replicate over multiple passages (Figure 5D). NP oligomers coat viral RNA to defend against host viral RNA sensors and nucleases; however, these oligomers also prevent the viral polymerase L from accessing viral RNA. During viral transcription and replication, accumulation of EBOV VP35 disrupts NP oligomers (Figure 3C), releasing free viral RNA as a template for RNA-directed RNA synthesis [24,25]. One possible hypothesis is that NP-R111E stabilizes oligomers too strongly, rendering viral RNA inaccessible to $L$, in turn abrogating minigenome transcription and replication. Because NP-R111E trVLPs were extremely defective, charge-reversal, unsurprisingly, has never been observed in EBOV or most other ebolavirus sequences (Figure 2C). Surprisingly, Sudan virus (SUDV), a replication-competent ebolavirus that is lethal in humans, does encode a charge-reversal substitution, NP-K110E (Figure 2C). The secondary structure of an SUDV NP monomer is quite similar to that of EBOV NP [87], and residues 109-111 are positioned in the same $\beta$-strand in both. However, SUDV NP oligomers have not yet been characterized, so one of the many other amino acid differences between SUDV and EBOV could counteract the effect of NP-K110E in SUDV. Future study is required to better understand how EBOV NP oligomerization affects viral RNA synthesis, and how SUDV NP promotes viral transcription and replication despite a charge-reversal substitution.

By contrast, the epidemic-associated EBOV substitution, NP-R111C, produced more intermediate phenotypes-slightly increased oligomerization (Figure 3D), moderately reduced transcription and replication (Figure 5C,D), and moderately increased VLP production (Figure 4C). EBOV virion assembly is a complex process, and how NP enhances budding of VLPs [35] (Figure 4C) is not fully understood. By studying the host interactome of NP, we confirmed a strong interaction between NP and the clathrin adaptor AP-1 complex (Supplementary Figure S5B), which mediates intracellular transport and could facilitate virion assembly. AP-1 members were among the few proteins that co-purified with NP in multiple MS/MS experiments $[82,83,85]$, but the interaction was not specifically validated by a second approach like reciprocal co-IP in those studies. In retroviruses, the Gag protein facilitates 
budding by hijacking the AP-1 complex [88]. Because retroviral and EBOV virions bud using the same cellular pathway and machinery [76], EBOV NP might also co-opt the AP-1 complex for virion egress and trafficking, which could explain how NP promotes VLP formation [35]. Yet both NP-R111 and NP-R111C bound to AP-1 with similar affinity (Supplementary Figure S5C). Thus, the interaction with AP-1 did not explain NP-R111C's increased ability to promote VLP production. Much work remains to be done to better understand how NP enacts so many roles during the viral life cycle.

Our data point to a complex interplay between NP oligomerization and NP's roles in structure and replication, and highlight the importance of developing reporter assays for viruses, especially pathogens of high consequence. Many viral proteins are highly multi-functional, making study of individual mutations challenging without robust assays that are sensitive to subtle changes in viral phenotype. Since luciferase-based reporter systems fit the aforementioned requirements, we took advantage of these systems to develop a BRET assay for NP oligomerization and a VLP detection assay, which offer a number of advantages over existing methods. Previous attempts to assess NP oligomerization typically used biochemical methods with purified protein [24,25] or by co-immunoprecipitation from cell lysates [53,70,71]. In our BRET assay, the NLuc substrate and HaloTag ligand have minimal cytotoxicity and readily diffuse into live cells, key features that minimized spurious interactions and allowed us to assess oligomerization over a range of physiologically-relevant EBOV NP concentrations (Figure 3D). To measure VLP production, previous attempts to fuse FLuc (60 kDa) to VP40 (40 kDa) resulted in near undetectable levels of luminescent VLPs [75]. In our VLP budding assay, we took advantage of the brightness and small size of NLuc $(19 \mathrm{kDa})$ to show that NLuc fused to VP40 generated luminescent VLPs, and that NP-R111C modestly increased VLP production (Figure 4C).

These BSL-2 assays are simple and flexible for testing viral mutations of interest like NP-R111C, which emerged and quickly became a dominant substitution during the 2013-2016 EVD epidemic. In particular, the BRET assay for NP oligomerization can be performed in high-throughput. BRET signal is quite reproducible between replicates and plates because the assay includes normalization based on NLuc luminescence to adjust for differences in transfection or protein expression efficiency, and subtraction of background luminescence to compensate for luminescence spillover from NLuc into the BRET channel. With more rigorous screening and quantification of key metrics of variability like Z-factor, these assays could be used for high-throughput screens of hundreds of EBOV NP mutants, interactions with host factors, or antagonism by drug candidates. The flexibility of BSL-2 reporter assays makes them ideal as first-line methods to probe mutations and mechanisms prior to cumbersome BSL-4 studies with live virus.

Testing whether emergent mutations like NP-R111C affect fitness of live virus brings additional challenges because different viral stocks and cultured cells versus animal models can cause discordant results. For example, the GP-A82V substitution has been shown numerous times to enhance EBOV infectivity in cell culture [15-20], using multiple EBOV surrogate systems (e.g., EBOV VLPs, retroviral particles pseudotyped with EBOV GP, and recombinant live virus [17]) and multiple cell types (e.g., human monocyte-derived dendritic cells [15]). However, a recent study using immunocompromised laboratory mice and non-human primates [21] indicated that EBOV Makona viral isolates encoding GP-A82V lead to modestly decreased viral load compared those without the GP-A82V mutation. A second recent study found that GP-A82V may induce slightly more morbidity and fatality in immunocompromised laboratory mice but not in domestic ferrets [22]. The discrepancies between the in vitro and in vivo studies could be due to the use of clinical EBOV isolates [21] that contain multiple additional mutations versus live EBOV generated from recombinant DNA plasmids [17]. Limited recombinant live EBOV studies have been performed to test the impact of the NP-R111C substitution specifically. One study showed that EBOV with GP-A82V and NP-R111C outcompetes ancestral EBOV Makona in a head-to-head format in cultured cells, but did not measure the impact of NP-R111C alone [17]. Another study found that NP-R111C alone increases viral replication in cell culture, decreases morbidity and lethality in immunocompromised laboratory mice, and does not differ from ancestral EBOV Makona in domestic ferrets [22]. 
Revealing the importance of the NP 111 residue and establishing experimental systems represent steps towards characterizing a key EBOV substitution, NP-R111C, that arose during the 2013-2016 Western African EVD epidemic. Given current limitations and restrictions of BSL-4 settings and the potential global threat of EVD epidemics, BSL-2 model systems can facilitate rapid and broad exploration of any potentially consequential EBOV mutations. We demonstrate that NP-R111C modestly increased VLP production while slightly decreasing viral transcription and replication. On the other hand, a charge-reversal substitution at the same site, observed in SUDV but not other EBOV or other ebolaviruses, caused drastically increased oligomerization and ablated transcription and replication. These findings provide additional insight into the interplay between the many functions of NP in oligomerization, viral assembly and budding, and transcription and replication, and suggest that NP-R111C and other substitutions at the 111 residue merit further study using live virus.

Supplementary Materials: The following are available online at http://www.mdpi.com/1999-4915/12/1/105/s1, Figure S1. Deletion of the reported NP oligomerization domain (NP- $\Delta \mathrm{OD})$ prevents NP oligomerization in cell culture; Figure S2. NP-NLuc variants express at similar concentrations; Figure S3. Optimization of NLuc-VP40 VLP assay; Figure S4. Electron microscopy of NP-R111 and NP-R111C VLPs; Figure S5. EBOV NP interacts with the adaptor protein 1 (AP-1) complex independent of the NP 111 allele; File S1. Key resources table; File S2. List of all proteins identified by co-immunoprecipitation tandem mass spectrometry (co-IP MS/MS), related to Figure S5A.

Author Contributions: Conceptualization, A.E.L., W.E.D., J.L., and P.C.S.; methodology, A.E.L., W.E.D., Y.C., C.L.F., C.A., R.N.K., J.H.K., and J.L.; software, A.E.L. and K.G.A.; validation, W.E.D., Y.C., C.L.F., and R.N.K.; formal analysis, A.E.L., W.E.D., R.N.K., and K.G.A.; investigation, A.E.L., W.E.D., Y.C., C.L.F., C.A., and R.N.K.; data curation, A.E.L.; writing-original draft, A.E.L., W.E.D., S.F.S., E.A.B., K.G.A., J.L., and P.C.S.; writing-review \& editing, A.E.L., W.E.D., Y.C., C.L.F., C.A., R.N.K., L.B., S.F.S., E.A.B., E.O.S., K.G.A., J.H.K., J.L., and P.C.S.; visualization, A.E.L., W.E.D., L.B., and S.F.S.; supervision, E.O.S., K.G.A., J.H.K., J.L., and P.C.S.; project administration, J.L. and P.C.S. All authors have read and agreed to the published version of the manuscript.

Funding: This material was based upon work supported by the Howard Hughes Medical Institute Investigator Award (P.C.S) and the US National Institutes of Health (NIH) grants National Institute of Allergy and Infectious Diseases (NIAID) U19AI110818 (P.C.S.), National Institute on Drug Abuse (NIDA) DP1DA034990 (J.L.), NIAID R01AI148784 and R37AI147868 (J.L.), and NIAID R01AI118016 (E.O.S.). A.E.L. was supported by National Science Foundation (NSF) under Grant No. DGE 1144152. C.A. was supported by award Number T32GM007753 from the NIH's National Institute of General Medical Sciences (NIGMS). E.O.S. was supported by an Investigators in the Pathogenesis of Infectious Disease Award from the Burroughs Wellcome Fund, by the Skaggs Institute for Chemical Biology, and by the Shaffer Family Foundation. K.G.A. was a Pew Biomedical Scholar and was supported by NIH National Center for Advancing Translational Studies Clinical and Translational Science (NCATS) Award UL1TR001114, and NIAID contract HHSN272201400048C. This work was also funded in part through Battelle Memorial Institute's prime contract with the US NIAID under Contract No. HHSN272200700016I (Y.C., C.L.F., L.B., J.H.K.). The funders had no role in study design, data collection and interpretation, or the decision to submit the work for publication.

Acknowledgments: We thank Ross Tomaino of the Harvard Taplin Mass Spectrometry Facility for sample and instrument handling following immunoprecipitation of NP-containing protein complexes. We thank Gregory Hendricks of the University of Massachusetts Medical School Core Electron Microscopy Facility for sample and instrument handling following production of Ebola virion-like particles. Electron Microscopy (EM) was supported by Award Number S10RR027897 from the National Center for Research Resources to the University of Massachusetts Medical School Core EM Facility. Ebola virus phylogenetics was made possible by the Virus Pathogen Database and Analysis Resource (ViPR) [42], which has been wholly funded with federal funds from NIAID, the US National Institutes of Health, and the US Department of Health and Human Services (HHS), under Contract No. HHSN272201400028C. The authors are solely the responsibility for the content of this paper and do not necessarily represent the official views of the National Center for Research Resources or of US HHS or of the institutions and companies affiliated with the authors.

Conflicts of Interest: The authors declare no conflict of interest.

\section{References}

1. Holmes, E.C. The Evolution and Emergence of RNA Viruses; Oxford University Press: Oxford, UK, 2009; ISBN 9780199211128.

2. World Health Organization (WHO). Ebola Situation Report-30 March 2016. Available online: http: //apps.who.int/ebola/current-situation/ebola-situation-report-30-march-2016 (accessed on 9 December 2019). 
3. Baize, S.; Pannetier, D.; Oestereich, L.; Rieger, T.; Koivogui, L.; Magassouba, N.; Soropogui, B.; Sow, M.S.; Keïta, S.; De Clerck, H.; et al. Emergence of Zaire Ebola virus disease in Guinea. N. Engl. J. Med. 2014, 371, 1418-1425. [CrossRef]

4. Gire, S.K.; Goba, A.; Andersen, K.G.; Sealfon, R.S.G.; Park, D.J.; Kanneh, L.; Jalloh, S.; Momoh, M.; Fullah, M.; Dudas, G.; et al. Genomic surveillance elucidates Ebola virus origin and transmission during the 2014 outbreak. Science 2014, 345, 1369-1372. [CrossRef] [PubMed]

5. Carroll, M.W.; Matthews, D.A.; Hiscox, J.A.; Elmore, M.J.; Pollakis, G.; Rambaut, A.; Hewson, R.; García-Dorival, I.; Bore, J.A.; Koundouno, R.; et al. Temporal and spatial analysis of the 2014-2015 Ebola virus outbreak in West Africa. Nature 2015, 524, 97-101. [CrossRef]

6. Ladner, J.T.; Wiley, M.R.; Mate, S.; Dudas, G.; Prieto, K.; Lovett, S.; Nagle, E.R.; Beitzel, B.; Gilbert, M.L.; Fakoli, L.; et al. Evolution and spread of Ebola virus in Liberia, 2014-2015. Cell Host Microbe 2015, 18, 659-669. [CrossRef]

7. Tong, Y.-G.; Shi, W.-F.; Liu, D.; Qian, J.; Liang, L.; Bo, X.-C.; Liu, J.; Ren, H.-G.; Fan, H.; Ni, M.; et al. Genetic diversity and evolutionary dynamics of Ebola virus in Sierra Leone. Nature 2015, 524, 93-96. [CrossRef] [PubMed]

8. Park, D.J.; Dudas, G.; Wohl, S.; Goba, A.; Whitmer, S.L.M.; Andersen, K.G.; Sealfon, R.S.; Ladner, J.T.; Kugelman, J.R.; Matranga, C.B.; et al. Ebola virus epidemiology, transmission, and evolution during seven months in Sierra Leone. Cell 2015, 161, 1516-1526. [CrossRef] [PubMed]

9. Simon-Loriere, E.; Faye, O.; Faye, O.; Koivogui, L.; Magassouba, N.; Keita, S.; Thiberge, J.-M.; Diancourt, L.; Bouchier, C.; Vandenbogaert, M.; et al. Distinct lineages of Ebola virus in Guinea during the 2014 West African epidemic. Nature 2015, 524, 102-104. [CrossRef]

10. Kugelman, J.R.; Sanchez-Lockhart, M.; Andersen, K.G.; Gire, S.; Park, D.J.; Sealfon, R.; Lin, A.E.; Wohl, S.; Sabeti, P.C.; Kuhn, J.H.; et al. Evaluation of the potential impact of Ebola virus genomic drift on the efficacy of sequence-based candidate therapeutics. MBio 2015, 6, e02227-14. [CrossRef]

11. Hoenen, T.; Safronetz, D.; Groseth, A.; Wollenberg, K.R.; Koita, O.A.; Diarra, B.; Fall, I.S.; Haidara, F.C.; Diallo, F.; Sanogo, M.; et al. Mutation rate and genotype variation of Ebola virus from Mali case sequences. Science 2015, 348, 117-119. [CrossRef]

12. Hoenen, T.; Groseth, A.; Rosenke, K.; Fischer, R.J.; Hoenen, A.; Judson, S.D.; Martellaro, C.; Falzarano, D.; Marzi, A.; Squires, R.B.; et al. Nanopore sequencing as a rapidly deployable Ebola outbreak tool. Emerg. Infect. Dis. 2016, 22, 331-334. [CrossRef]

13. Smits, S.L.; Pas, S.D.; Reusken, C.B.; Haagmans, B.L.; Pertile, P.; Cancedda, C.; Dierberg, K.; Wurie, I.; Kamara, A.; Kargbo, D.; et al. Genotypic anomaly in Ebola virus strains circulating in Magazine Wharf area, Freetown, Sierra Leone, 2015. Euro Surveill. 2015, 20. [CrossRef] [PubMed]

14. Quick, J.; Loman, N.J.; Duraffour, S.; Simpson, J.T.; Severi, E.; Cowley, L.; Bore, J.A.; Koundouno, R.; Dudas, G.; Mikhail, A.; et al. Real-time, portable genome sequencing for Ebola surveillance. Nature 2016, 530, 228-232. [CrossRef] [PubMed]

15. Diehl, W.E.; Lin, A.E.; Grubaugh, N.D.; Carvalho, L.M.; Kim, K.; Kyawe, P.P.; McCauley, S.M.; Donnard, E.; Kucukural, A.; McDonel, P.; et al. Ebola virus glycoprotein with increased infectivity dominated the 2013-2016 epidemic. Cell 2016, 167, 1088-1098.e6. [CrossRef]

16. Urbanowicz, R.A.; McClure, C.P.; Sakuntabhai, A.; Sall, A.A.; Kobinger, G.; Müller, M.A.; Holmes, E.C.; Rey, F.A.; Simon-Loriere, E.; Ball, J.K. Human adaptation of Ebola virus during the West African outbreak. Cell 2016, 167, 1079-1087.e5. [CrossRef]

17. Dietzel, E.; Schudt, G.; Krähling, V.; Matrosovich, M.; Becker, S. Functional characterization of adaptive mutations during the West African Ebola virus outbreak. J. Virol. 2017, 91, e01913-e01916. [CrossRef]

18. Ueda, M.T.; Kurosaki, Y.; Izumi, T.; Nakano, Y.; Oloniniyi, O.K.; Yasuda, J.; Koyanagi, Y.; Sato, K.; Nakagawa, S. Functional mutations in spike glycoprotein of Zaire ebolavirus associated with an increase in infection efficiency. Genes Cells 2017, 22, 148-159. [CrossRef]

19. Hoffmann, M.; Crone, L.; Dietzel, E.; Paijo, J.; González-Hernández, M.; Nehlmeier, I.; Kalinke, U.; Becker, S.; Pöhlmann, S. A polymorphism within the internal fusion loop of the Ebola virus glycoprotein modulates host cell entry. J. Virol. 2017, 91, e00177-17. [CrossRef]

20. Wang, M.K.; Lim, S.-Y.; Lee, S.M.; Cunningham, J.M. Biochemical basis for increased activity of Ebola glycoprotein in the 2013-16 epidemic. Cell Host Microbe 2017, 21, 367-375. [CrossRef] 
21. Marzi, A.; Chadinah, S.; Haddock, E.; Feldmann, F.; Arndt, N.; Martellaro, C.; Scott, D.P.; Hanley, P.W.; Nyenswah, T.G.; Sow, S.; et al. Recently identified mutations in the Ebola virus-Makona genome do not alter pathogenicity in animal models. Cell Rep. 2018, 23, 1806-1816. [CrossRef] [PubMed]

22. Wong, G.; He, S.; Leung, A.; Cao, W.; Bi, Y.; Zhang, Z.; Zhu, W.; Wang, L.; Zhao, Y.; Cheng, K.; et al. Naturally-occurring single mutations in Ebola observably impact infectivity. J. Virol. 2018, 93, e01098-18. [CrossRef] [PubMed]

23. Dong, S.; Yang, P.; Li, G.; Liu, B.; Wang, W.; Liu, X.; Xia, B.; Yang, C.; Lou, Z.; Guo, Y.; et al. Insight into the Ebola virus nucleocapsid assembly mechanism: Crystal structure of Ebola virus nucleoprotein core domain at $1.8 \AA$ A resolution. Protein Cell 2015, 6, 351-362. [CrossRef] [PubMed]

24. Leung, D.W.; Borek, D.; Luthra, P.; Binning, J.M.; Anantpadma, M.; Liu, G.; Harvey, I.B.; Su, Z.; Endlich-Frazier, A.; Pan, J.; et al. An intrinsically disordered peptide from Ebola virus VP35 controls Viral RNA synthesis by modulating nucleoprotein-RNA interactions. Cell Rep. 2015, 11, 376-389. [CrossRef] [PubMed]

25. Kirchdoerfer, R.N.; Abelson, D.M.; Li, S.; Wood, M.R.; Saphire, E.O. Assembly of the Ebola virus nucleoprotein from a chaperoned VP35 complex. Cell Rep. 2015, 12, 140-149. [CrossRef] [PubMed]

26. Wan, W.; Kolesnikova, L.; Clarke, M.; Koehler, A.; Noda, T.; Becker, S.; Briggs, J.A.G. Structure and assembly of the Ebola virus nucleocapsid. Nature 2017, 551, 394-397. [CrossRef] [PubMed]

27. Su, Z.; Wu, C.; Shi, L.; Luthra, P.; Pintilie, G.D.; Johnson, B.; Porter, J.R.; Ge, P.; Chen, M.; Liu, G.; et al. Electron Cryo-microscopy Structure of Ebola virus nucleoprotein reveals a mechanism for nucleocapsid-like assembly. Cell 2018, 172, 966-978.e12. [CrossRef] [PubMed]

28. Sugita, Y.; Matsunami, H.; Kawaoka, Y.; Noda, T.; Wolf, M. Cryo-EM structure of the Ebola virus nucleoprotein-RNA complex at $3.6 \AA$ resolution. Nature 2018, 563, 137-140. [CrossRef] [PubMed]

29. Kirchdoerfer, R.N.; Saphire, E.O.; Ward, A.B. Cryo-EM structure of the Ebola virus nucleoprotein-RNA complex. Acta Crystallogr. Sect. F Struct. Biol. Cryst. Commun. 2019, 75, 340-347. [CrossRef]

30. Kirchdoerfer, R.N.; Saphire, E.O.; Ward, A.B. Structure of the Ebola virus nucleoprotein-RNA complex. bioRxiv 2019, 548313. [CrossRef]

31. Jasenosky, L.D.; Kawaoka, Y. Filovirus budding. Virus Res. 2004, 106, 181-188. [CrossRef]

32. Harty, R.N.; Brown, M.E.; Wang, G.; Huibregtse, J.; Hayes, F.P. A PPxY motif within the VP40 protein of Ebola virus interacts physically and functionally with a ubiquitin ligase: Implications for filovirus budding. Proc. Natl. Acad. Sci. USA 2000, 97, 13871-13876. [CrossRef]

33. Jasenosky, L.D.; Neumann, G.; Lukashevich, I.; Kawaoka, Y. Ebola virus VP40-induced particle formation and association with the lipid bilayer. J. Virol. 2001, 75, 5205-5214. [CrossRef] [PubMed]

34. Noda, T.; Sagara, H.; Suzuki, E.; Takada, A.; Kida, H.; Kawaoka, Y. Ebola virus VP40 drives the formation of virus-like filamentous particles along with GP. J. Virol. 2002, 76, 4855-4865. [CrossRef] [PubMed]

35. Licata, J.M.; Johnson, R.F.; Han, Z.; Harty, R.N. Contribution of Ebola virus glycoprotein, nucleoprotein, and VP24 to budding of VP40 virus-like particles. J. Virol. 2004, 78, 7344-7351. [CrossRef] [PubMed]

36. Groseth, A.; Charton, J.E.; Sauerborn, M.; Feldmann, F.; Jones, S.M.; Hoenen, T.; Feldmann, H. The Ebola virus ribonucleoprotein complex: a novel VP30-L interaction identified. Virus Res. 2009, 140, 8-14. [CrossRef] [PubMed]

37. Kirchdoerfer, R.N.; Moyer, C.L.; Abelson, D.M.; Saphire, E.O. The Ebola virus VP30-NP interaction is a regulator of viral RNA synthesis. PLoS Pathog. 2016, 12, e1005937. [CrossRef] [PubMed]

38. Volchkov, V.E.; Volchkova, V.A.; Mühlberger, E.; Kolesnikova, L.V.; Weik, M.; Dolnik, O.; Klenk, H.-D. Recovery of infectious Ebola virus from complementary DNA: RNA editing of the GP gene and viral cytotoxicity. Science 2001, 291, 1965-1969. [CrossRef] [PubMed]

39. Neumann, G.; Feldmann, H.; Watanabe, S.; Lukashevich, I.; Kawaoka, Y. Reverse genetics demonstrates that proteolytic processing of the Ebola virus glycoprotein is not essential for replication in cell culture. J. Virol. 2002, 76, 406-410. [CrossRef]

40. Towner, J.S.; Paragas, J.; Dover, J.E.; Gupta, M.; Goldsmith, C.S.; Huggins, J.W.; Nichol, S.T. Generation of eGFP expressing recombinant Zaire ebolavirus for analysis of early pathogenesis events and high-throughput antiviral drug screening. Virology 2005, 332, 20-27. [CrossRef]

41. Hoenen, T.; Groseth, A.; Callison, J.; Takada, A.; Feldmann, H. A novel Ebola virus expressing luciferase allows for rapid and quantitative testing of antivirals. Antiviral Res. 2013, 99, 207-213. [CrossRef] 
42. $\quad$ Pickett, B.E.; Sadat, E.L.; Zhang, Y.; Noronha, J.M.; Squires, R.B.; Hunt, V.; Liu, M.; Kumar, S.; Zaremba, S.; $\mathrm{Gu}, \mathrm{Z}$; ; et al. ViPR: An open bioinformatics database and analysis resource for virology research. Nucleic Acids Res. 2012, 40, D593-D598. [CrossRef]

43. Katoh, K.; Standley, D.M. MAFFT multiple sequence alignment software version 7: Improvements in performance and usability. Mol. Biol. Evol. 2013, 30, 772-780. [CrossRef] [PubMed]

44. Capella-Gutiérrez, S.; Silla-Martínez, J.M.; Gabaldón, T. trimAl: A tool for automated alignment trimming in large-scale phylogenetic analyses. Bioinformatics 2009, 25, 1972-1973. [CrossRef]

45. Stamatakis, A.; Ludwig, T.; Meier, H. RAxML-III: A fast program for maximum likelihood-based inference of large phylogenetic trees. Bioinformatics 2005, 21, 456-463. [CrossRef] [PubMed]

46. Schrödinger, L.L.C. The PyMOL Molecular Graphics System, Version 2.0. Available online: https://pymol. org/2 (accessed on 5 October 2017).

47. Warren, L.; Manos, P.D.; Ahfeldt, T.; Loh, Y.-H.; Li, H.; Lau, F.; Ebina, W.; Mandal, P.K.; Smith, Z.D.; Meissner, A.; et al. Highly efficient reprogramming to pluripotency and directed differentiation of human cells with synthetic modified mRNA. Cell Stem Cell 2010, 7, 618-630. [CrossRef] [PubMed]

48. Kim, J.H.; Lee, S.-R.; Li, L.-H.; Park, H.-J.; Park, J.-H.; Lee, K.Y.; Kim, M.-K.; Shin, B.A.; Choi, S.-Y. High cleavage efficiency of a $2 \mathrm{~A}$ peptide derived from porcine teschovirus-1 in human cell lines, zebrafish and mice. PLoS ONE 2011, 6, e18556. [CrossRef] [PubMed]

49. Subach, O.M.; Cranfill, P.J.; Davidson, M.W.; Verkhusha, V.V. An enhanced monomeric blue fluorescent protein with the high chemical stability of the chromophore. PLoS ONE 2011, 6, e28674. [CrossRef]

50. Manicassamy, B.; Rong, L. Expression of ebolavirus glycoprotein on the target cells enhances viral entry. Virol. J. 2009, 6, 75. [CrossRef]

51. Bornholdt, Z.A.; Noda, T.; Abelson, D.M.; Halfmann, P.; Wood, M.R.; Kawaoka, Y.; Saphire, E.O. Structural rearrangement of Ebola virus VP40 begets multiple functions in the virus life cycle. Cell 2013, 154, 763-774. [CrossRef]

52. Jasenosky, L.D.; Neumann, G.; Kawaoka, Y. Minigenome-based reporter system suitable for high-throughput screening of compounds able to inhibit ebolavirus replication and/or transcription. Antimicrob. Agents Chemother. 2010, 54, 3007-3010. [CrossRef]

53. Watanabe, S.; Noda, T.; Kawaoka, Y. Functional mapping of the nucleoprotein of Ebola virus. J. Virol. 2006, 80, 3743-3751. [CrossRef]

54. Lin, A.E.; Greco, T.M.; Döhner, K.; Sodeik, B.; Cristea, I.M. A proteomic perspective of inbuilt viral protein regulation: pUL46 tegument protein is targeted for degradation by ICP0 during herpes simplex virus type 1 infection. Mol. Cell. Proteom. 2013, 12, 3237-3252. [CrossRef] [PubMed]

55. Gao, G.; Hendricks, G.M. Introducing genes into mammalian cells: Viral vectors. Protocol 14: Analysis of rAAV sample morphology using negative staining and high resolution electron microscopy. In Molecular Cloning (A Laboratory Manual); Green, M.R., Sambrook, J., Eds.; Cold Spring Harbor Press: Cold Spring Harbor, NY, USA, 2012; Volume 2, pp. 1301-1303. ISBN 9781936113422.

56. Schneider, C.A.; Rasband, W.S.; Eliceiri, K.W. NIH Image to ImageJ: 25 years of image analysis. Nat. Methods 2012, 9, 671-675. [CrossRef] [PubMed]

57. Watt, A.; Moukambi, F.; Banadyga, L.; Groseth, A.; Callison, J.; Herwig, A.; Ebihara, H.; Feldmann, H.; Hoenen, T. A novel life cycle modeling system for Ebola virus shows a genome length-dependent role of VP24 in virus infectivity. J. Virol. 2014, 88, 10511-10524. [CrossRef]

58. Watanabe, S.; Watanabe, T.; Noda, T.; Takada, A.; Feldmann, H.; Jasenosky, L.D.; Kawaoka, Y. Production of novel Ebola virus-like particles from cDNAs: an alternative to Ebola virus generation by reverse genetics. J. Virol. 2004, 78, 999-1005. [CrossRef] [PubMed]

59. Shevchenko, A.; Wilm, M.; Vorm, O.; Mann, M. Mass spectrometric sequencing of proteins silver-stained polyacrylamide gels. Anal. Chem. 1996, 68, 850-858. [CrossRef] [PubMed]

60. Peng, J.; Gygi, S.P. Proteomics: The move to mixtures. J. Mass Spectrom. 2001, 36, 1083-1091. [CrossRef]

61. Eng, J.K.; McCormack, A.L.; Yates, J.R. An approach to correlate tandem mass spectral data of peptides with amino acid sequences in a protein database. J. Am. Soc. Mass Spectrom. 1994, 5, 976-989. [CrossRef]

62. Mellacheruvu, D.; Wright, Z.; Couzens, A.L.; Lambert, J.-P.; St-Denis, N.A.; Li, T.; Miteva, Y.V.; Hauri, S.; Sardiu, M.E.; Low, T.Y.; et al. The CRAPome: A contaminant repository for affinity purification-mass spectrometry data. Nat. Methods 2013, 10, 730-736. [CrossRef] 
63. Snel, B. STRING: A web-server to retrieve and display the repeatedly occurring neighbourhood of a gene. Nucleic Acids Res. 2000, 28, 3442-3444. [CrossRef]

64. Szklarczyk, D.; Franceschini, A.; Wyder, S.; Forslund, K.; Heller, D.; Huerta-Cepas, J.; Simonovic, M.; Roth, A.; Santos, A.; Tsafou, K.P.; et al. STRING v10: Protein-protein interaction networks, integrated over the tree of life. Nucleic Acids Res. 2015, 43, D447-D452. [CrossRef]

65. Shannon, P.; Markiel, A.; Ozier, O.; Baliga, N.S.; Wang, J.T.; Ramage, D.; Amin, N.; Schwikowski, B.; Ideker, T. Cytoscape: A software environment for integrated models of biomolecular interaction networks. Genome Res. 2003, 13, 2498-2504. [CrossRef] [PubMed]

66. R Core Team. R: A Language and Environment for Statistical Computing; R Foundation for Statistical Computing: Vienna, Austria, 2016; Available online: https://www.R-project.org (accessed on 27 October 2016).

67. Baty, F.; Ritz, C.; Charles, S.; Brutsche, M.; Flandrois, J.-P.; Delignette-Muller, M.-L. A toolbox for nonlinear regression in R: The package nlstools. J. Stat. Softw. 2015, 66, 1-21. [CrossRef]

68. Wickham, H. Ggplot2: Elegant Graphics for Data Analysis; Springer: Berlin, Germany, 2016; ISBN 9783319242774.

69. Computational Resources in R: R Packages. Available online: http://www.dex.ufla.br/ \{\}danielff/en/softwares/ r_resources_en.html (accessed on 22 November 2017).

70. Ng, A.K.-L.; Lam, M.K.-H.; Zhang, H.; Liu, J.; Au, S.W.-N.; Chan, P.K.-S.; Wang, J.; Shaw, P.-C. Structural basis for RNA binding and homo-oligomer formation by influenza B virus nucleoprotein. J. Virol. 2012, 86, 6758-6767. [CrossRef] [PubMed]

71. Ortiz-Riaño, E.; Cheng, B.Y.H.; de la Torre, J.C.; Martinez-Sobrido, L. Self-association of lymphocytic choriomeningitis virus nucleoprotein is mediated by its $\mathrm{N}$-terminal region and is not required for its anti-interferon function. J. Virol. 2012, 86, 3307-3317. [CrossRef] [PubMed]

72. Machleidt, T.; Woodroofe, C.C.; Schwinn, M.K.; Méndez, J.; Robers, M.B.; Zimmerman, K.; Otto, P.; Daniels, D.L.; Kirkland, T.A.; Wood, K.V. NanoBRET-A novel BRET platform for the analysis of protein-protein interactions. ACS Chem. Biol. 2015, 10, 1797-1804. [CrossRef]

73. Mercier, J.F.; Salahpour, A.; Angers, S.; Breit, A.; Bouvier, M. Quantitative assessment of $\beta_{1}$ - and $\beta_{2}$-adrenergic receptor homo-and heterodimerization by bioluminescence resonance energy transfer. J. Biol Chem. 2002, 277, 44925-44931. [CrossRef]

74. Marullo, S.; Bouvier, M. Resonance energy transfer approaches in molecular pharmacology and beyond. Trends Pharmacol Sci. 2007, 28, 362-365. [CrossRef]

75. McCarthy, S.E.; Licata, J.M.; Harty, R.N. A luciferase-based budding assay for Ebola virus. J. Virol. Methods 2006, 137, 115-119. [CrossRef]

76. Liu, Y.; Cocka, L.; Okumura, A.; Zhang, Y.-A.; Sunyer, J.O.; Harty, R.N. Conserved motifs within Ebola and Marburg virus VP40 proteins are important for stability, localization, and subsequent budding of virus-like particles. J. Virol. 2010, 84, 2294-2303. [CrossRef]

77. Hall, M.P.; Unch, J.; Binkowski, B.F.; Valley, M.P.; Butler, B.L.; Wood, M.G.; Otto, P.; Zimmerman, K.; Vidugiris, G.; Machleidt, T.; et al. Engineered luciferase reporter from a deep sea shrimp utilizing a novel imidazopyrazinone substrate. ACS Chem. Biol. 2012, 7, 1848-1857. [CrossRef]

78. Reynard, O.; Reid, S.P.; Page, A.; Mateo, M.; Alazard-Dany, N.; Raoul, H.; Basler, C.F.; Volchkov, V.E. Unconventional secretion of Ebola virus matrix protein VP40. J. Infect. Dis. 2011, 204 (Suppl. 3), S833-S839. [CrossRef] [PubMed]

79. Pleet, M.L.; Mathiesen, A.; DeMarino, C.; Akpamagbo, Y.A.; Barclay, R.A.; Schwab, A.; Iordanskiy, S.; Sampey, G.C.; Lepene, B.; Nekhai, S.; et al. Ebola VP40 in exosomes can cause immune cell dysfunction. Front. Microbiol. 2016, 7, 1765. [CrossRef] [PubMed]

80. Hu, L.; Trefethen, J.M.; Zeng, Y.; Yee, L.; Ohtake, S.; Lechuga-Ballesteros, D.; Warfield, K.L.; Aman, M.J.; Shulenin, S.; Unfer, R.; et al. Biophysical characterization and conformational stability of Ebola and Marburg virus-like particles. J. Pharm. Sci. 2011, 100, 5156-5173. [CrossRef] [PubMed]

81. Hoenen, T.; Jung, S.; Herwig, A.; Groseth, A.; Becker, S. Both matrix proteins of Ebola virus contribute to the regulation of viral genome replication and transcription. Virology 2010, 403, 56-66. [CrossRef] [PubMed]

82. García-Dorival, I.; Wu, W.; Armstrong, S.D.; Barr, J.N.; Carroll, M.W.; Hewson, R.; Hiscox, J.A. Elucidation of the cellular interactome of Ebola virus nucleoprotein and identification of therapeutic targets. J. Proteome Res. 2016, 15, 4290-4303. [CrossRef] 
83. Batra, J.; Hultquist, J.F.; Liu, D.; Shtanko, O.; Von Dollen, J.; Satkamp, L.; Jang, G.M.; Luthra, P.; Schwarz, T.M.; Small, G.I.; et al. Protein interaction mapping identifies RBBP6 as a negative regulator of Ebola virus replication. Cell 2018, 175, 1917-1930.e13. [CrossRef]

84. Morwitzer, M.J.; Tritsch, S.R.; Cazares, L.H.; Ward, M.D.; Nuss, J.E.; Bavari, S.; Reid, S.P. Identification of RUVBL1 and RUVBL2 as novel cellular interactors of the Ebola virus nucleoprotein. Viruses 2019, 11, 372. [CrossRef]

85. Chen, J.; He, Z.; Yuan, Y.; Huang, F.; Luo, B.; Zhang, J.; Pan, T.; Zhang, H.; Zhang, J. Host factor SMYD3 is recruited by Ebola virus nucleoprotein to facilitate viral mRNA transcription. Emerg. Microbes Infect. 2019, 8, 1347-1360. [CrossRef]

86. Goldstein, T.; Anthony, S.J.; Gbakima, A.; Bird, B.H.; Bangura, J.; Tremeau-Bravard, A.; Belaganahalli, M.N.; Wells, H.L.; Dhanota, J.K.; Liang, E.; et al. The discovery of Bombali virus adds further support for bats as hosts of ebolaviruses. Nat. Microbiol. 2018, 3, 1084-1089. [CrossRef]

87. Landeras-Bueno, S.; Oda, S.-I.; Norris, M.J.; Li Salie, Z.; Guenaga, J.; Wyatt, R.T.; Saphire, E.O. Sudan ebolavirus VP35-NP crystal structure reveals a potential target for pan-filovirus treatment. MBio 2019, 10, e00734-19. [CrossRef]

88. Camus, G.; Segura-Morales, C.; Molle, D.; Lopez-Vergès, S.; Begon-Pescia, C.; Cazevieille, C.; Schu, P.; Bertrand, E.; Berlioz-Torrent, C.; Basyuk, E. The clathrin adaptor complex AP-1 binds HIV-1 and MLV gag and facilitates their budding. Mol. Biol. Cell 2007, 18, 3193-3203. [CrossRef] [PubMed]

(C) 2020 by the authors. Licensee MDPI, Basel, Switzerland. This article is an open access article distributed under the terms and conditions of the Creative Commons Attribution (CC BY) license (http://creativecommons.org/licenses/by/4.0/). 